\title{
Parameter Spaces of Environmental Fields Responsible for Cyclone Development from Tropics to Extratropics
}

\author{
WATARU YANASE AND HiROSHI NiINO \\ Atmosphere and Ocean Research Institute, University of Tokyo, Kashiwa, Japan \\ KeVIN Hodges \\ NERC Centre for Earth Observation, University of Reading, Reading, United Kingdom \\ NAOKO KITABATAKE \\ Meteorological Research Institute, Japan Meteorological Agency, Tsukuba, Japan
}

(Manuscript received 5 March 2013, in final form 2 August 2013)

\begin{abstract}
Objective cyclone tracking applied to a 30-yr reanalysis dataset shows that cyclone development in the summer and autumn seasons is active in the tropics and extratropics and inactive in the subtropics. To understand this geographically bimodal distribution of cyclone development associated with tropical and extratropical cyclones quantitatively, the direct relationship between cyclone types and their environments are assessed by using a parameter space of environmental variables [environmental parameter space (EPS)]. The number of cyclones is analyzed in terms of two different factors: the environmental conditions favorable for cyclone development and the area size that satisfies the favorable condition. The EPS analysis is mainly conducted for two representative environmental parameters that are commonly used for cyclone analysis: potential intensity for tropical cyclones and baroclinicity for extratropical cyclones. The geographically bimodal distribution is attributed to the high sensitivity of the cyclone development to the change in the environmental fields from tropics to extratropics. In addition, the bimodal distribution is partly attributed to the rapid change in the environmental fields from tropics to extratropics. The EPS analysis also shows that other environmental parameters, including relative humidity and vertical velocity, may enhance the contrast between the tropics (extratropics) and subtropics, whereas they are not essential for determining cyclone types. The relationship between cyclones and their environments is found to be similar between the hemispheres in the EPS, although the geographical distribution, particularly the longitudinal uniformity, is markedly different between the hemispheres.
\end{abstract}

\section{Introduction}

Satellite imagery and weather maps show various types of synoptic-scale cyclones developing over the global ocean. In particular, two representative types of cyclones are tropical cyclones (TCs) in the low latitudes and extratropical cyclones (ECs) in the midlatitudes. A typical TC has spiral-shaped convective clouds and a warmcore structure, whereas a typical EC is accompanied by a comma-shaped cloud and a cold-core structure with warm and cold fronts. There are also intermediate types

Corresponding author address: Wataru Yanase, Atmosphere and Ocean Research Institute, The University of Tokyo, 5-1-5, Kashiwanoha, Kashiwa, Chiba 277-8568, Japan.

E-mail: yanase@aori.u-tokyo.ac.jp between TCs and ECs, which are hereafter referred to as hybrid cyclones (HCs): for example, subtropical cyclones (Otkin and Martin 2004; Evans and Guishard 2009; Guishard et al. 2009; Evans and Braun 2012), extratropical transitioning TCs (Hart and Evans 2001; Jones et al. 2003; Hart et al. 2006; Kitabatake 2008, 2011), and tropical transitioning disturbances originating from the midlatitudes (Davis and Bosart 2004; Mctaggart-Cowan et al. 2013).

These different types of cyclones can be objectively classified based on their structures (Hart 2003) once identified in atmospheric gridded datasets, such as reanalysis and model simulations. Figure 1 shows distributions of developing cyclones including TCs, ECs, and HCs for four seasons in the Southern and Northern Hemispheres $(\mathrm{SH} / \mathrm{NH})$, where the cyclones have been 
(a) SH summer (DJF)

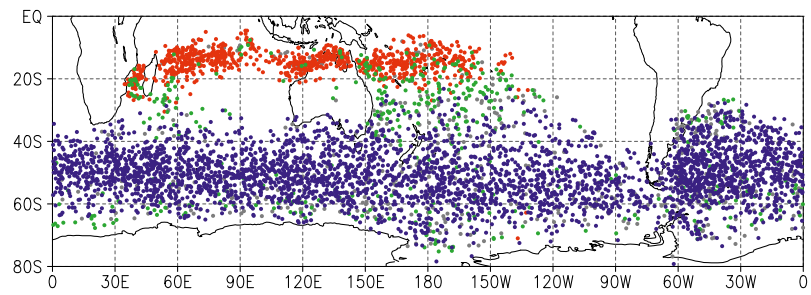

(c) SH autumn (MAM)

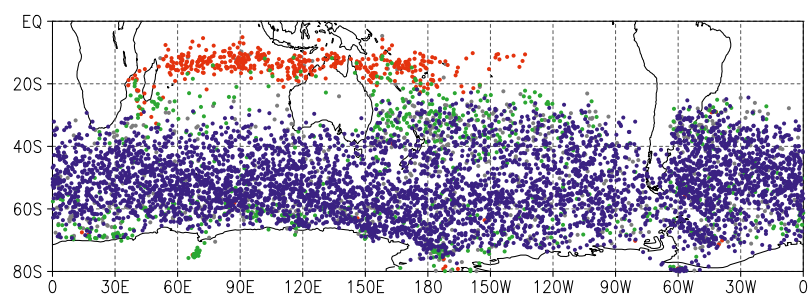

(e) SH winter (JJA)

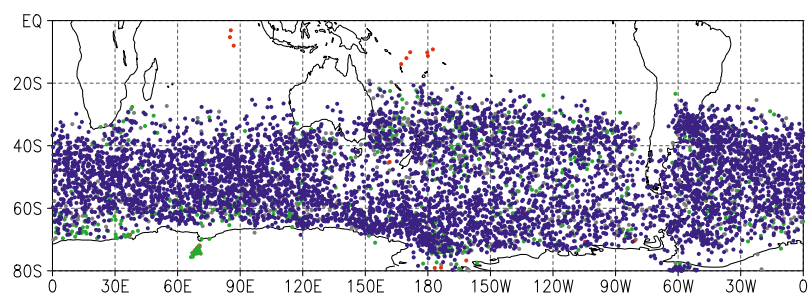

(g) SH spring (SON)

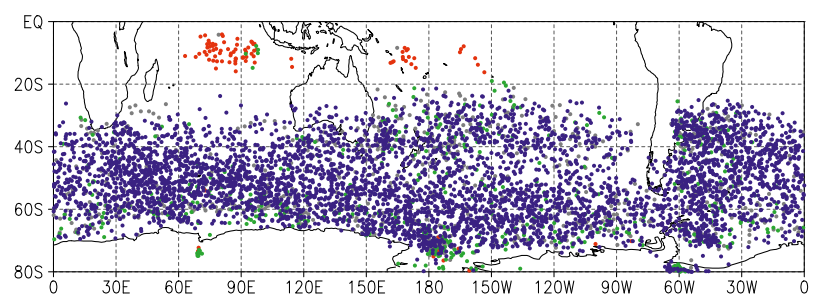

(b) NH summer (JJA)

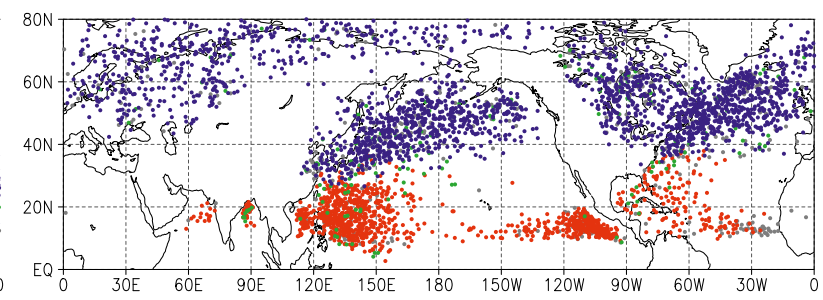

(d) $\mathrm{NH}$ autumn (SON)

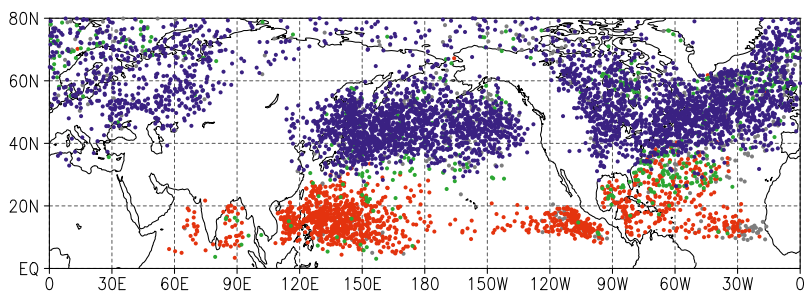

(f) $\mathrm{NH}$ winter (DJF)

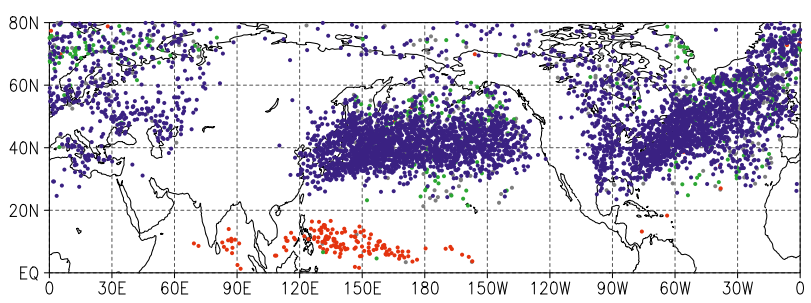

(h) NH spring (MAM)

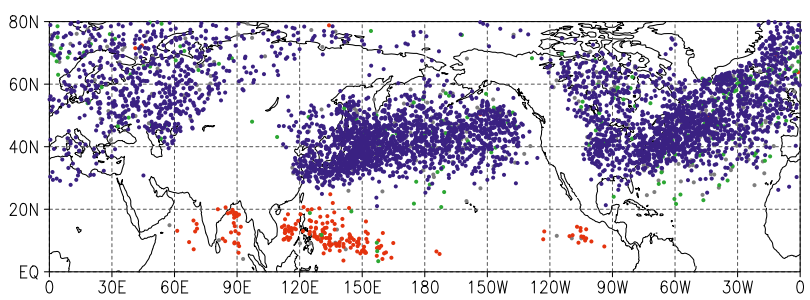

FIG. 1. Geographical locations of developing cyclones (growth rate $>0.1 \mathrm{day}^{-1}$ ) for $30 \mathrm{yr}$ (December 1981-November 2011) during (a) SH summer, (b) NH summer, (c) SH autumn, (d) NH autumn, (e) SH winter, (f) NH winter, (g) SH spring, and (h) NH spring. Colors of marks indicate TCs (red), ECs (blue), HCs (green), and ill-defined cyclones (gray).

tracked by the method of Hodges (1999) and classified by the method of Hart (2003) as described in detail in section 2. During the summer and autumn seasons in both hemispheres, there are two dominant regions of cyclone development in the tropics and extratropics. Over the warm oceans in the tropics, TCs develop through a positive feedback mechanism between vortex circulation and diabatic processes including condensational heating of cumulus convection and ocean surface heat fluxes. (Ooyama 1969; Emanuel 1986; Smith 1997). On the other hand, within the large temperature gradient in the extratropics, ECs develop as a response to baroclinic instability (Eady 1949; Charney 1949; Hoskins 1976).
Although there are some HCs in the subtropics, which seem to be subtropical cyclones, extratropical transitioning TCs, and tropical transitioning disturbances originating from the midlatitudes, the cyclone development is relatively inactive in the subtropics. Thus, the distribution of cyclone development is latitudinally bimodal with two peaks in the tropics and extratropics. Furthermore, the distribution of cyclones in the NH is less uniform in the longitudinal direction than that in the $\mathrm{SH}$, which seems to be attributed to planetary-scale dynamical and thermodynamical forcing of land-sea contrast, orography, and sea surface temperature (Inatsu et al. 2002; Sauliere et al. 2012). Thus, the cyclone development 
during the summer and autumn seasons are characterized by a bimodal distribution in a geographical (primarily latitudinal and secondarily longitudinal) space.

It is important to understand the environments in which cyclones develop, in particular if we want to understand the impacts of climate change on the cyclone activity. The aims of this study are to introduce an approach to analyzing the relationship between cyclones and their environment. This study focuses on the environmental fields in the present climate particularly during the summer season to elucidate the geographically bimodal distribution of cyclone development, which is one of the interesting subjects of the cyclone's environment.

There are several environmental parameters/variables responsible for cyclone development. Potential intensity is an environmental parameter commonly used for TC analysis, which considers sea surface temperature and vertical profiles of temperature and humidity in the troposphere (Bister and Emanuel 2002). For example, Figs. $2 \mathrm{a}$ and $2 \mathrm{~b}$ show geographical distributions of the climatological (30-yr average) potential intensity in the $\mathrm{SH}$ and $\mathrm{NH}$ summer, respectively. The potential intensity is largest in the tropics and decreases with increasing latitude, which explains well the climatological distribution of developing TCs (Figs. 1a,b), except that TCs rarely develop near the equator because of small planetary vorticity (Coriolis parameter). The baroclinicity or Eady growth rate is an environmental parameter used for EC analysis, which is proportional to the vertical wind shear, planetary vorticity, and inverse of static stability (Hoskins and Valdes 1990). Figures 2c and 2d show a geographical distribution of the climatological baroclinicity at $850 \mathrm{hPa}$ in the $\mathrm{SH}$ and $\mathrm{NH}$ summer, respectively. The baroclinicity is largest in the midlatitudes, which is consistent with the climatological distribution of developing ECs. In addition to the latitudinal distribution, the potential intensity and baroclinicity also explains the relatively uniform (nonuniform) characteristics in the longitudinal distribution in the $\mathrm{SH}(\mathrm{NH})$ summer. Therefore, it is natural to qualitatively attribute the cyclone distribution to these two environmental parameters favorable for TC and EC development.

However, a question arises as to what scenarios explain the significant suppression of the cyclone activity around the subtropics quantitatively, which is responsible for the notably bimodal distribution. Figures $3 \mathrm{a}$ and $3 \mathrm{~b}$ show the schematics of two possible scenarios for the relationship between cyclone development and environmental parameter such as potential intensity and baroclinicity: in scenario $\mathrm{A}$, the environmental parameter rapidly changes around the subtropics, which causes the rapid decrease of cyclone development (Fig. 3a); in scenario B, the environmental parameter gradually changes around the subtropics, but the cyclone dynamics are very sensitive to the slight change of the environmental parameter around the subtropics (Fig. 3b). In addition, the combination of several environmental parameters may enhance the contrast between active and inactive cyclone development. The purpose of the present study is to assess whether these scenarios are responsible for the notably bimodal distribution of cyclones observed in the summer and autumn seasons. Instead of the geographical distribution of cyclones and environmental variables, the frequency of cyclones are examined in a parameter space whose coordinate axis has a dimension of environmental parameter [environmental parameter space (EPS)], which provides a more direct relationship between cyclones and their environments. First, the EPS in the SH summer is analyzed in detail because the cyclone distribution shows relatively uniform bands in the longitudinal direction (Fig. 1a). The longitudinally uniform characteristic is convenient to interpret the relation between latitude and environmental variables. Second, the relationships between the cyclone dynamics and their environments are compared between the hemispheres and seasons. In particular, the cyclone distribution in the $\mathrm{NH}$ summer is less uniform in the longitudinal direction than in the SH summer, although it still shows the geographically bimodal distribution of cyclone development. Therefore, it is of interest to examine whether the relationships are similar or not between the hemispheres and seasons in terms of the EPS.

The remainder of the paper is organized as follows: section 2 describes the methodology including reanalysis dataset, tracking algorithm, and the EPS analysis. Section 3 presents the results of the EPS analysis mainly for the $\mathrm{SH}$ and $\mathrm{NH}$ summer. Section 4 interprets the relation between geographical space and the EPS and discusses the utility of the EPS analysis. Finally, section 5 summarizes the relationship between cyclones and their environmental fields.

\section{Methodology}

\section{a. Observation and analysis data}

The statistics of cyclones and their environmental fields over the ocean is analyzed for $30 \mathrm{yr}$ (December 1981-November 2011) using atmospheric reanalysis and sea surface temperature data. The atmospheric dataset is the 6-hourly reanalysis data, which are calculated using the $3 \mathrm{D}$ variational data assimilation system to assimilate the disparate observations developed at the Japan Meteorological Agency (JMA) Japanese 25-yr Reanalysis (JRA-25; Onogi et al. 2007) for the period 
(a) Potential intensity in SH summer (DJF)

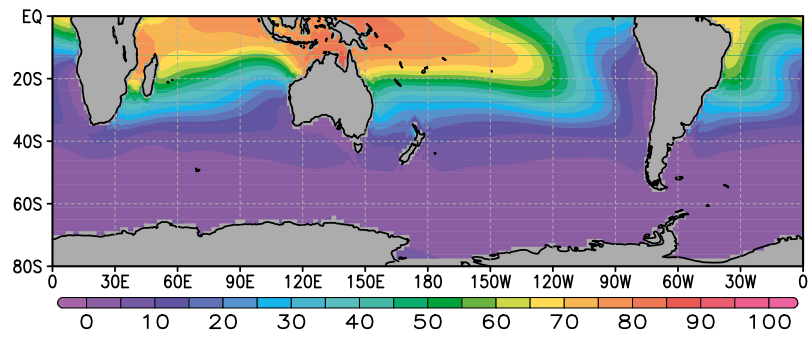

(c) Baroclinicity in SH summer (DJF)

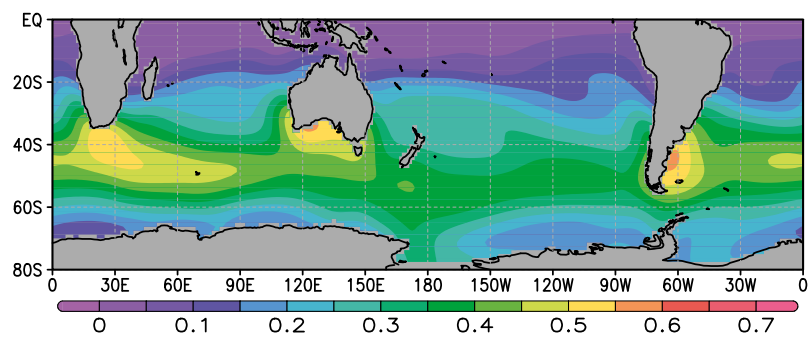

(e) Relative humidity in SH summer (DJF)

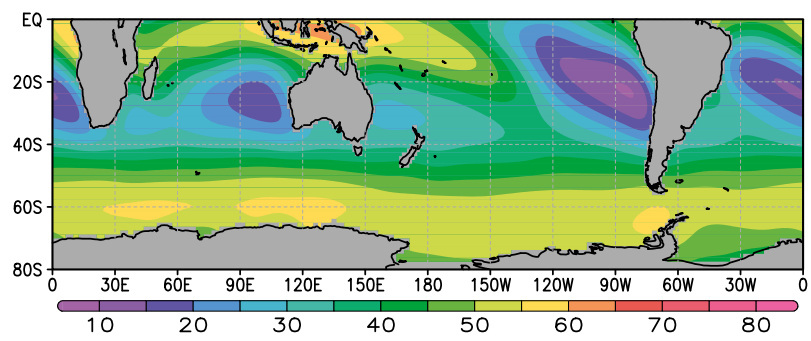

(g) Vertical velocity in SH summer (DJF)

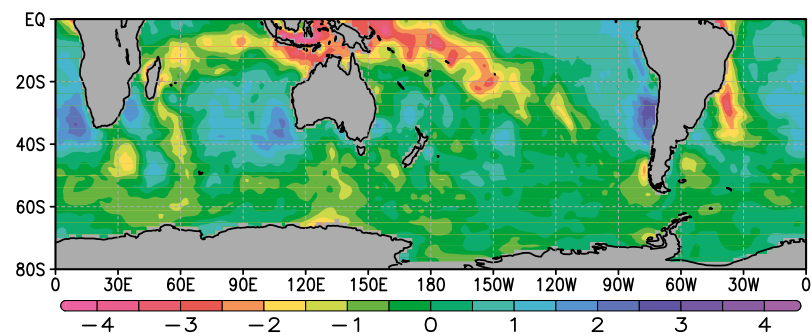

(b) Potential intensity in NH summer (JJA)

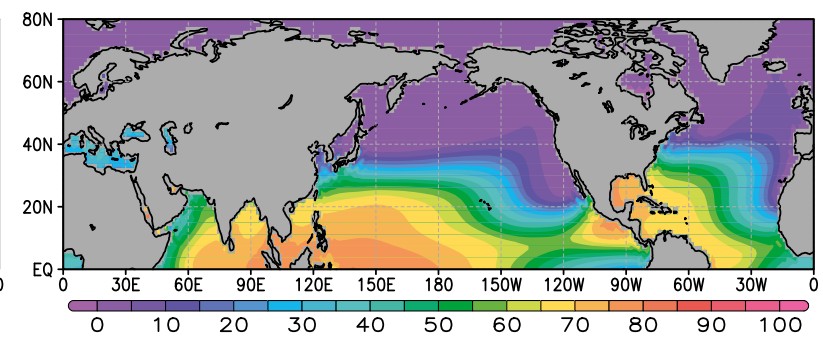

(d) Baroclinicity in NH summer (JJA)

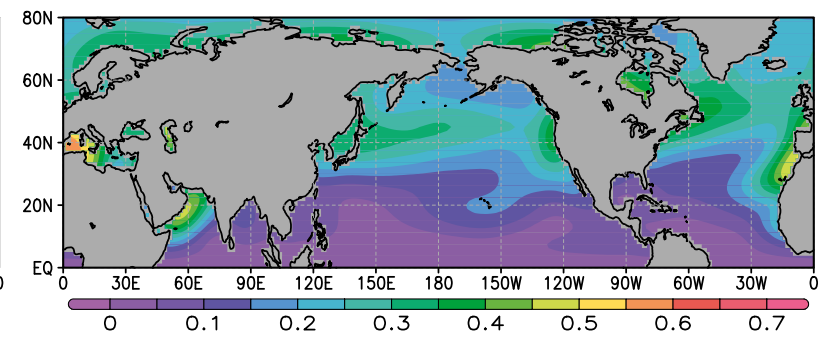

(f) Relative humidity in NH summer (JJA)

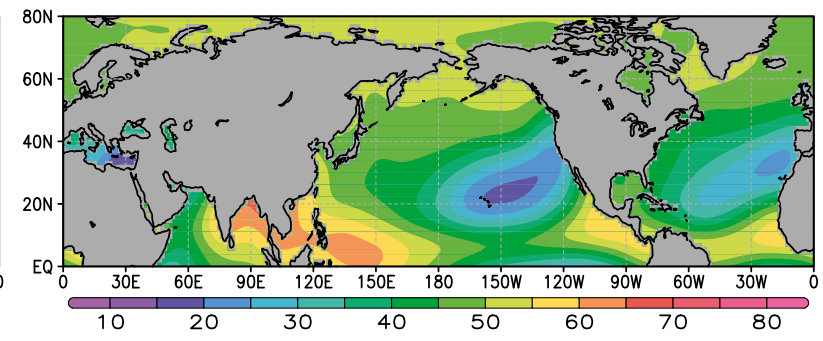

(h) Vertical velocity in NH summer (JJA)

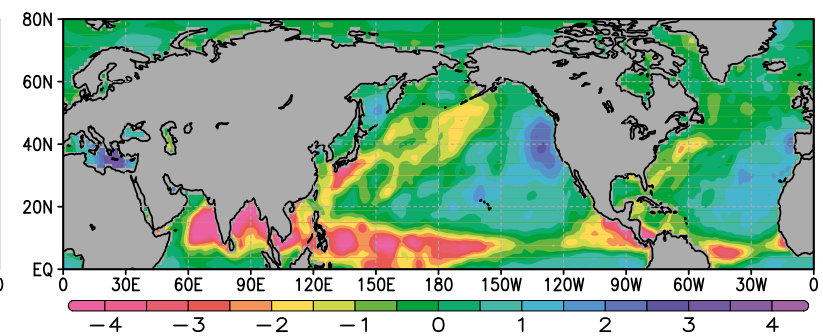

FIG. 2. Geographical distribution of the climatological (December 1981-November 2011) environmental fields in (left) SH and (right) NH summer for (a),(b) potential intensity $\left(\mathrm{m} \mathrm{s}^{-1}\right.$ ) defined by Eq. (1); (c),(d) baroclinicity (day ${ }^{-1}$ ) defined by Eq. (2); (e),(f) relative humidity at $600 \mathrm{hPa}(\%)$; and $(\mathrm{g}),(\mathrm{h})$ pressure vertical velocity at $500 \mathrm{hPa}\left(\mathrm{hPa} \mathrm{h}^{-1}\right)$.

from December 1981 to December 2004 and the JMA Climate Data Assimilation System (JCDAS) for the period from January 2005 to November 2011. Since both JRA-25 and JCDAS are based on the same assimilation system using a T106 spectral model, equivalent to a horizontal resolution of $1.25^{\circ}$ with 40 vertical sigma levels, they provide a homogeneous dataset for the entire period. The dataset of sea surface temperature is the daily optimum interpolation (OISST; Reynolds et al. 2002) of the National Oceanic and Atmospheric Administration (NOAA).

The ability of the JRA-25/JCDAS reanalysis to represent the intensity and structures of cyclones is evaluated by comparing two supplementary datasets. One is the European Centre for Medium-Range Weather Forecasts (ECMWF) Interim Re-Analysis (ERAInterim; Simmons et al. 2007), which uses a spectral model at a horizontal resolution of T255 $\left(0.75^{\circ}\right)$ with 
(a) Scenario A (geogr. space)

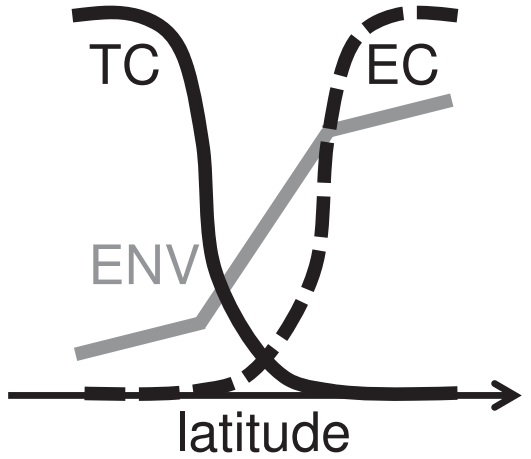

(c) Scenario A (EPS)

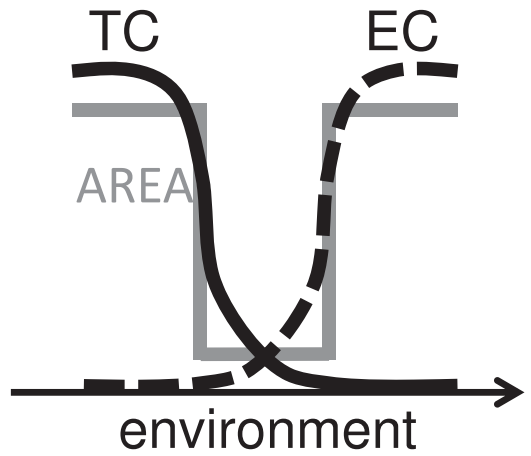

(b) Scenario B (geogr. space)

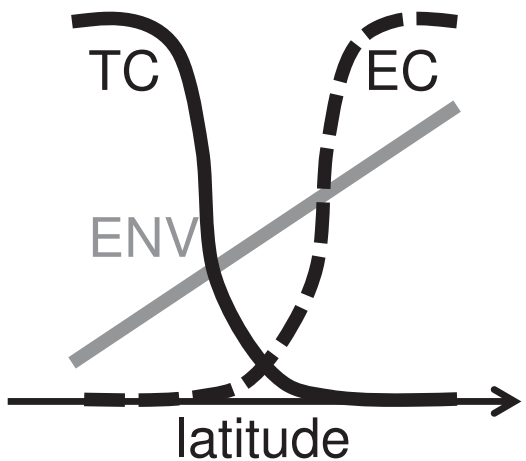

(d) Scenario B (EPS)

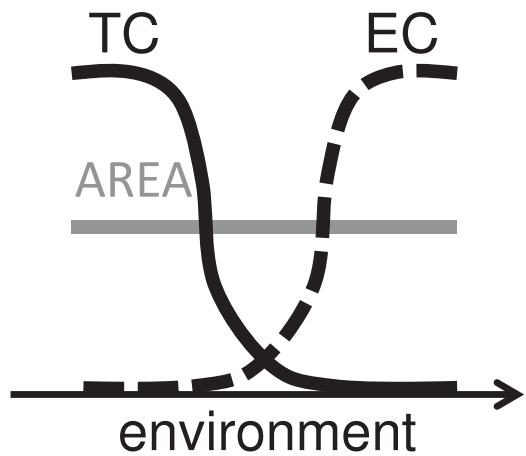

FIG. 3. Schematics of scenarios A and B for geographical space and EPS with (a) scenario A for geographical space, (b) scenario B for geographical space, (c) scenario A for EPS, and (d) scenario B for EPS. In (a) and (b), ENV indicates the environmental parameter. In (c) and (d), AREA indicates environment area in the EPS.

60 vertical hybrid levels and the four-dimensional (4D) variational data assimilation system. The other is the International Best Track Archive for Climate Stewardship (IBTrACS; Knapp et al. 2010), which is a global best-track dataset based on the TC information from multiple meteorological centers. The best track is expected to provide more reliable information regarding the locations and intensities of individual TCs.

The summer, autumn, winter, and spring seasons in the SH are December-February (DJF), March-May (MAM), June-August (JJA), and September-November (SON), respectively, whereas those in the NH are JJA, SON, DJF and MAM, respectively.

\section{b. Tracking and classification of cyclones}

Tracks of cyclones are objectively detected by applying a cyclone tracking algorithm (Hodges 1994, 1995, 1999) and methodology (Hoskins and Hodges 2002) to the 6-hourly relative vorticity at $900 \mathrm{hPa}$. The relative vorticity is truncated to T42 horizontal resolution in order to reduce problems associated with noise and to focus on synoptic-scale cyclones (Jung et al. 2012). First, all vorticity maxima that exceed $1.0 \times 10^{-5} \mathrm{~s}^{-1}$ are determined for consecutive time steps as described in Hodges (1995), where the vorticity in the $\mathrm{SH}$ is multiplied by -1 so that the cyclonic circulation can be associated with a positive anomaly in both hemispheres. Next, these maxima are linked between contiguous time steps to form tracks by using the minimization of a cost function that depends on the track smoothness and is subject to adaptive constraints on displacement and smoothness (Hodges 1999). To remove short-lived cyclones such as mesoscale cyclones, only tracks with a lifetime of 2 days or longer are retained.

The intensity and types of cyclones, which are described in the following paragraphs, are first calculated using the 6-hourly atmospheric field. Then, the 6-hourly data are averaged to a daily resolution to smooth out short time fluctuations of cyclone characteristics. The present study assesses the daily characteristics of the cyclones; therefore, one cyclone can be represented many times during its lifetime, as long as it satisfies the criteria of intensity or types. 
(a)

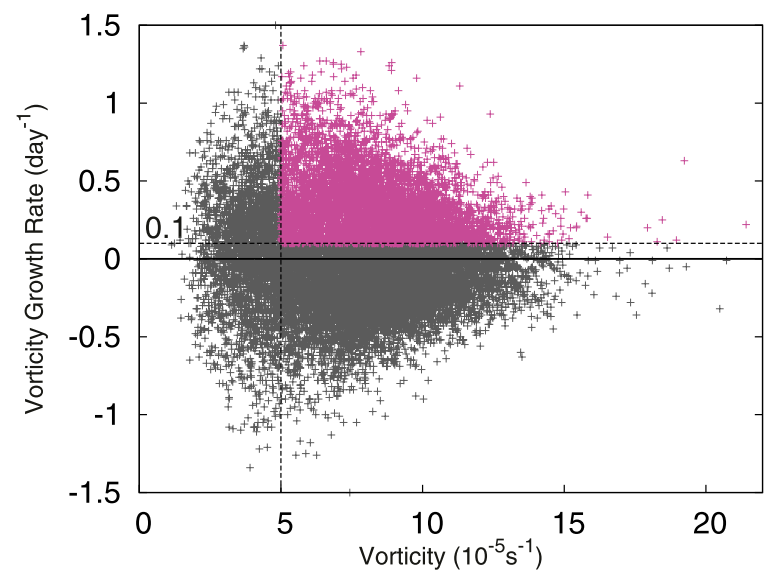

(b)

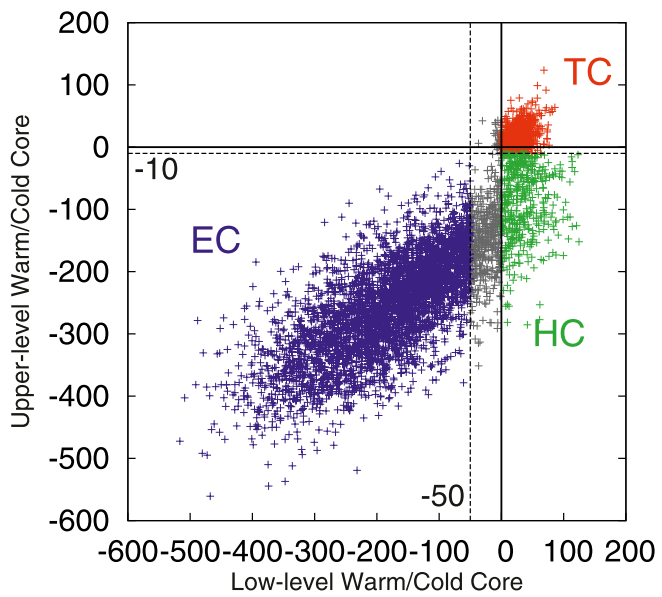

FIG. 4. (a) Definition of developing cyclones (purple marks) in the vorticity and growth rate plane. (b) Definition of cyclone types in the $-V_{T}^{L}$ (horizontal axis) and $-V_{T}^{U}$ (vertical axis) plane. Colors of marks indicate TCs (red), ECs (blue), HCs (green), and illdefined cyclones (gray).

In the present study, cyclones at developing stages are analyzed, since we are interested in the environmental fields favorable for cyclone development. The developing stage is defined by the period in which the growth rate of cyclone vorticity exceeds 0.1 day $^{-1}$ in the daily data. In addition, only intense cyclones with the vorticity exceeding $5 \times 10^{-5} \mathrm{~s}^{-1}$ at T42 resolution in the daily data are analyzed to obtain robust results. Figure $4 \mathrm{a}$ shows the above definition of developing cyclones (purple marks) on the vorticity-growth rate space for the SH summer using the JRA-25/JCDAS reanalysis as an example. As has been mentioned, if a cyclone satisfies the criteria for $n$ days during its life time, the cyclone is indicated by $n$ purple marks in the figure.
TABLE 1. Environmental parameters used in the EPS analysis with their units, analyzed ranges, and widths and numbers of bins.

\begin{tabular}{lllll}
\hline \multicolumn{1}{c}{$\begin{array}{c}\text { Parameter name } \\
\text { (abbreviation) }\end{array}$} & Unit & $\begin{array}{c}\text { Analyzed } \\
\text { range }\end{array}$ & $\begin{array}{c}\text { Bin } \\
\text { width }\end{array}$ & $\begin{array}{c}\text { Bin } \\
\text { no. }\end{array}$ \\
\hline $\begin{array}{l}\text { Potential intensity (PI) } \\
\text { Baroclinicity (BC) }\end{array}$ & $\begin{array}{l}\mathrm{m} \mathrm{s}^{-1} \\
\mathrm{day}^{-1}\end{array}$ & $0-100$ & 5 & 20 \\
$\begin{array}{c}\text { Relative humidity at } \\
\quad 600 \mathrm{hPa}(\mathrm{RH})\end{array}$ & $\%$ & $0-100$ & 5 & 20 \\
$\begin{array}{l}\text { Pressure vertical velocity } \\
\text { at 500 hPa (Pvel) }\end{array}$ & $\mathrm{hPa} \mathrm{h}^{-1}$ & -5 to 5 & 0.5 & 20 \\
\begin{tabular}{l} 
Latitude \\
\hline
\end{tabular} & ${ }^{\circ}$ lat & $0-80$ & 5 & 16 \\
\hline
\end{tabular}

The developing cyclones are classified every time step using the thermal wind index $-V_{T}$, which is determined from the geopotential height anomalies (Hart 2003). If a cyclone shows positive (negative) values of $-V_{T}$, this indicates it has a warm-core (cold core) structure. The index $-V_{T}$ is evaluated over the layers in the lower $\left(600-900 \mathrm{hPa} ;-V_{T}^{L}\right)$ and upper $\left(300-600 \mathrm{hPa} ;-V_{T}^{U}\right)$ troposphere. Thus, cyclones are classified as TCs for $-V_{T}^{L}>0$ and $-V_{T}^{U}>-10$, HCs for $-V_{T}^{L}>0$ and $-V_{T}^{U}<$ -10 , ECs for $-V_{T}^{L}<-50$, and ill-defined cyclones for the others, where the threshold of $-V_{T}^{U}$ is based on Guishard et al. (2009). The results of the classification are shown in Fig. $4 \mathrm{~b}$ for the developing cyclones in the SH summer shown in Fig. 4a. Note that the HCs have a warm-core structure in the lower troposphere and a cold-core structure in the upper troposphere, which corresponds to subtropical storms (Evans and Guishard 2009; Guishard et al. 2009), extratropical transitioning TCs (Jones et al. 2003; Hart et al. 2006), tropical transitioning disturbances (Hart 2003), and ECs undergoing a warm seclusion (Hart 2003). Figure 1 shows the geographical distribution of the cyclones after classification into $\mathrm{TC}, \mathrm{EC}$, or $\mathrm{HC}$ during their development stages. Although the thresholds of thermal wind indices are somewhat arbitrary, most of TCs and ECs develop in the tropical and extratropical regions, respectively. The present study adopts this classification as a state-of-the-art classification method.

\section{c. Environmental fields}

Among various variables affecting cyclone dynamics such as wind, temperature, and humidity, a few representative environmental parameters are shown in Table 1 and are examined as a first step of the EPS analysis. Latitude is also described in the table for later use, although it is not an environmental parameter. Figure 2 shows the climatological distribution of the environmental parameters in the $\mathrm{SH}$ and $\mathrm{NH}$ summer. Note that their latitudinal distribution is generally related to the ascending branch of the Hadley circulation in the tropics 
where active convection occurs, the descending dry branch of the Hadley circulation in the subtropics, and large meridional temperature gradients in the extratropics. On the other hand, their longitudinal distribution is affected by dynamical and thermodynamical forcing of the longitudinally nonuniform distribution of continents and orography (Valdes and Hoskins 1989; Hoskins 1996; Wang and Ting 1999; Inatsu et al. 2002; Miyasaka and Nakamura 2005; Sauliere et al. 2012).

Potential intensity (PI) is an environmental parameter often used for TC analysis (Bister and Emanuel 2002; Camargo et al. 2007), which is defined as

$$
\mathrm{PI}=\frac{T_{s}}{T_{0}} \frac{C_{k}}{C_{D}}\left(\mathrm{CAPE}^{*}-\mathrm{CAPE}^{b}\right),
$$

where $T_{s}$ is sea surface temperature, $T_{0}$ is mean outflow temperature at the level of neutral buoyancy, $C_{k}$ is the exchange coefficient for enthalpy, $C_{D}$ is the drag coefficient, $\mathrm{CAPE}^{*}$ is the convective available potential energy (CAPE) for an air parcel at the radius of maximum winds, and $\mathrm{CAPE}^{b}$ is the CAPE for an air parcel lifted from the lowest grid $(1000 \mathrm{hPa})$ in the ambient atmosphere. In general, potential intensity is large over the tropical oceans (Figs. 2a,b), where sea surface temperature is high.

Baroclinicity (BC) or Eady growth rate is an environmental parameter used for EC analysis (Hoskins and Valdes 1990), which is defined as

$$
\mathrm{BC}=0.31 f V_{z} N^{-1},
$$

where $f$ is the Coriolis parameter, $V_{z}$ is the vertical gradient of horizontal wind, and $N$ is Brunt-Väisälä frequency. The baroclinicity is defined at the $850-\mathrm{hPa}$ pressure level, in which the vertical differences of $V_{z}$ and $N$ are calculated using 925 and $700 \mathrm{hPa}$, which are adjacent levels of $850 \mathrm{hPa}$ in the JRA-25/JCDAS dataset. The baroclinicity is largest over the midlatitude oceans (Figs. 2c,d), where the horizontal gradient of atmospheric temperature is large. As mentioned in section 1 , potential intensity and baroclinicity qualitatively explain the geographical distribution of TCs and ECs, respectively (Figs. 1a,b). The combination of potential intensity and baroclinicity has been also used to understand the environmental field of extratropical transitioning TCs (Hart and Evans 2001).

Relative humidity and vertical velocity at the midtroposphere are also examined as environmental parameters because they may have some influence not on cyclone types but on cyclone development. Relative humidity at $600 \mathrm{hPa}$ is used for TC analysis (Emanuel and Nolan 2004; Camargo et al. 2007) because the midtropospheric humidity affects condensational heating in cumulus convection through an entrainment process. Vertical velocity at $500 \mathrm{hPa}$ is also used for TC analysis (Murakami and Wang 2010), which seems to affect cyclone dynamics either directly through vortex stretching or indirectly through modifying the activity of cumulus convection. Although the vertical velocity in the reanalysis data may not be represented sufficiently, it is interesting to examine the relationship between the vertical velocity and cyclone development. Figures $2 \mathrm{e}-\mathrm{h}$ show the relative humidity at $600 \mathrm{hPa}$ and pressure vertical velocity at $500 \mathrm{hPa}$ in the $\mathrm{SH}$ and $\mathrm{NH}$ summer. The tropics (subtropics) are characterized by high (low) humidity and updraft (downdraft), which are associated with the ascending (descending) branch of the Hadley cell. The subtropical characteristics with low humidity and downdraft are enhanced over the eastern parts of the ocean because the subtropical high pressure system is intensified to the west of the continent (Hoskins 1996; Miyasaka and Nakamura 2005). The region with low humidity and downdraft seem to be partly related to the inactive region of cyclone development (Figs. 1a,b).

Previous studies proposed that environmental fields change from intraseasonal (Camargo et al. 2009; Yanase et al. 2012) to interannual time scales (Camargo et al. 2007; Strachan et al. 2013), which modulate the activity of cyclones. Therefore, daily based analysis can provide more accurate information on the influence of environmental modulation on cyclone activity than the climatology-based analysis. On the other hand, raw daily data contain signals of cyclones themselves, which apparently contaminate the environmental field. Therefore, it is useful to remove the cyclone signal from the daily data by using time and space filters. The time filter used is a 20-day running mean, which is long enough to remove short-lived or mobile cyclones. In addition, the space filter of Kurihara et al. (1993), which smooths out disturbances smaller than $10^{\circ}$ latitude in size, is used as a supplement to remove stationary and long-lived cyclones. The time and space filter successfully removes the signals of cyclones. Basic variables including winds, temperature, and specific humidity are filtered first, and then the filtered basic variables are used to calculate PI, $\mathrm{BC}$, and relative humidity, which are nonlinear functions of the basic variables.

\section{d. Environmental parameter space}

To assess a direct relationship between cyclones and their environmental fields, an environmental parameter space (EPS) is used in this study. In contrast to geographical distributions such as Figs. 1 and 2, the EPS plots "cyclone frequency" in a coordinate of an environmental parameter such as potential intensity and baroclinicity, 
where cyclone frequency is defined by the number of cyclones counted for each bin of an environmental parameter (the bin sizes for analyzed parameters are shown in Table 1). Previous studies have also analyzed the frequency of cyclones in a coordinate of an environmental parameter such as sea surface temperature (Guishard et al. 2009; Evans and Braun 2012).

It should be emphasized that the number of cyclones in a given bin of an environmental parameter depends not only on how favorable the environment value is for cyclone development, but also on how large an area of the environmental value covers. Therefore, the area size covered by the values of the given bin is calculated using all the grid points over the oceans in the analyzed domain and period regardless of whether cyclones occur or not. The area size averaged for the period is referred to as "environment area." The combination of the cyclone frequency and environment area in the EPS can offer valuable insight into the relationship between cyclones and their environmental fields.

The units of the cyclone frequency and environment area are events day ${ }^{-1}$ range $^{-1}$ and $\mathrm{km}^{2}$ day $^{-1}$ range $^{-1}$, respectively, where the range is the whole analyzed range (i.e., bin width $\times$ bin number) of the parameter space (Table 1). The range is chosen so that the environment area integrated over the range exceeds $99 \%$ of the oceanic area in the hemisphere. Note that the integration of the cyclone frequency (environment area) over the range becomes the number of cyclones (the size of area) observed in the hemisphere per day.

\section{Results}

To confirm the main characteristics of the geographical distribution of the cyclone types for all the seasons and hemispheres more quantitatively than in Fig. 1, Fig. 5 shows the latitudinal distribution of cyclones, in other words, the cyclone frequency in the EPS of the parameter "latitude." The total numbers of TCs, ECs, and HCs are also given in Table 2. As has been mentioned in section 1 , the distribution of total cyclones (black curve) is latitudinally bimodal with peaks in the tropics and extratropics during the summer and autumn seasons. The peaks in the tropics and extratropics are clearly associated with TCs (red curve) and ECs (blue curve), respectively. Although HCs (green curve) develop in the subtropics and higher latitudes, they seem to contribute little to the latitudinally bimodal distribution. Therefore, the present study mainly focuses on TCs and ECs. Note that the environment area in the latitudinal coordinate indicates the area size of the ocean at each latitude, which should be a cosine function of the latitude if the entire earth was covered by the ocean.

\section{a. Roles of individual environmental parameters}

This section examines which environmental parameters are essential for the geographically bimodal distribution in the summer season (Figs. 1a,b and 5a,b). Figures $3 \mathrm{c}$ and $3 \mathrm{~d}$ schematically show the EPS distribution for scenarios A and B, respectively. If an essential parameter is taken as a coordinate of the EPS, the cyclone frequency in the EPS is also expected to show a bimodal distribution (black solid and dashed curves). For scenario A, where the environmental field in the geographical space rapidly changes around the subtropics with the intermediate value of the environmental parameter (Fig. 3a), the environment area in the EPS should show a bimodal distribution with a minimum around the intermediate value of the environmental coordinate (Fig. 3c). On the other hand, for scenario B, where the environmental field in the geographical space gradually changes (Fig. 3b), the environment area in the EPS should show a uniform distribution along the environmental coordinate (Fig. 3d). It should be noted that Fig. 3 shows a simplified concept for the two scenarios with only one axis (latitude in the geographical space and one parameter in the EPS); the real atmosphere has longitudinal variation in the geographical space and may be represented by more than one parameter in the EPS. In what follows, the SH summer is examined as a first step because the longitudinally uniform distribution of environmental fields makes it easy to relate environmental parameters to latitude.

Among various environmental parameters affecting cyclone distribution, potential intensity and baroclinicity show bimodal distribution of cyclone frequencies and therefore are considered to be essential parameters for the geographically bimodal distribution of cyclones. Figure $6 a$ shows the cyclone frequency and environment area in the EPS of potential intensity. In the coordinate of potential intensity, the total cyclone frequency (black curve) has a sharply bimodal distribution with two peaks around 0 and $70 \mathrm{~m} \mathrm{~s}^{-1}$ : the former is associated with ECs (blue curve), whereas the latter is associated with TCs (red curve). The environment area (gray curve) also shows a nearly bimodal distribution with peaks around 0 and $70 \mathrm{~m} \mathrm{~s}^{-1}$. Therefore, the low frequency of total cyclones in the region with intermediate potential intensities $\left(20-50 \mathrm{~m} \mathrm{~s}^{-1}\right)$ is partly attributed to the low environment area in the region. This characteristic supports scenario A (Fig. 3c), in which the environmental field rapidly changes around the subtropics (Fig. 3a). However, the bimodal distribution of the environment area is not sharp enough to explain the bimodal distribution of the cyclone frequency. This characteristic supports scenario B (Fig. 3d), in which the cyclone 
(a) SH summer (DJF)

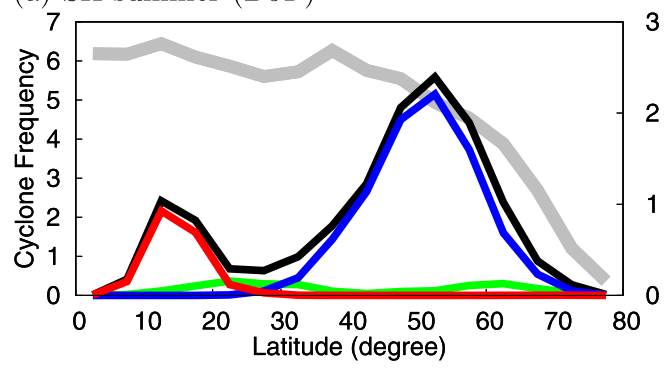

(c) SH autumn (MAM)

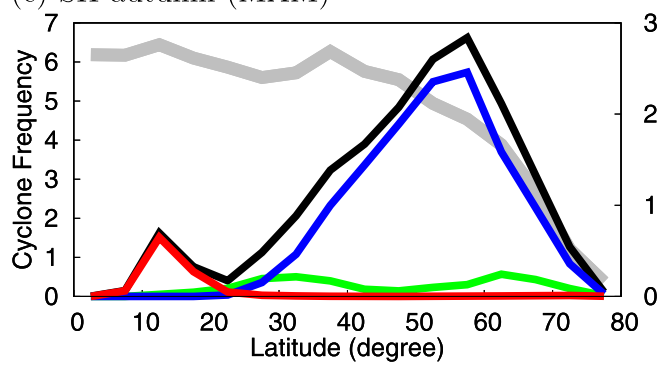

(e) SH winter (JJA)

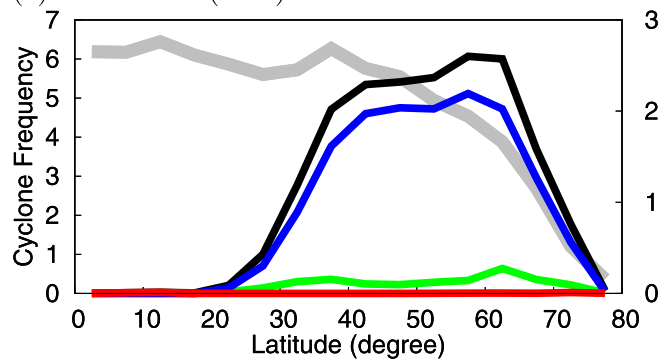

(g) SH spring (SON)

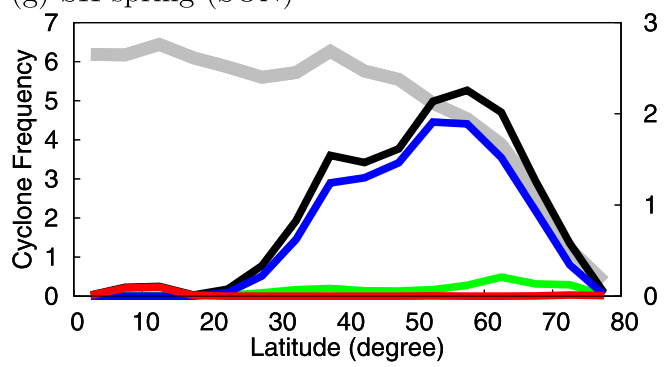

(b) NH summer (JJA)

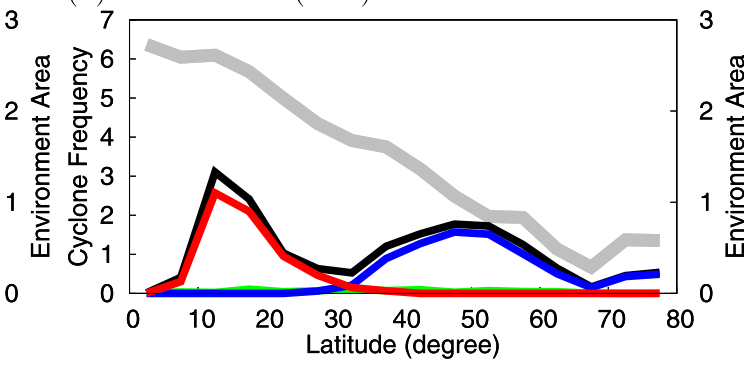

(d) $\mathrm{NH}$ autumn (SON)

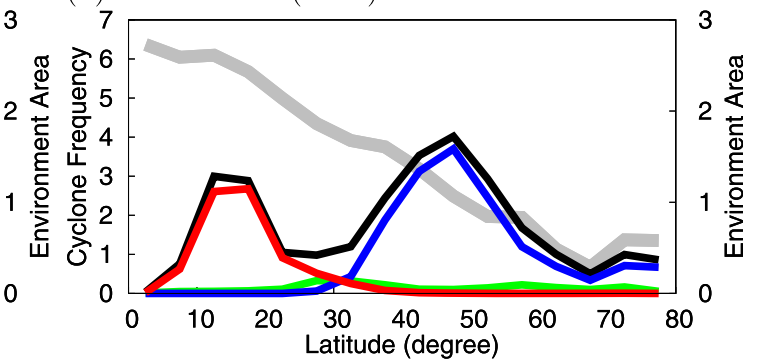

(f) $\mathrm{NH}$ winter (DJF)

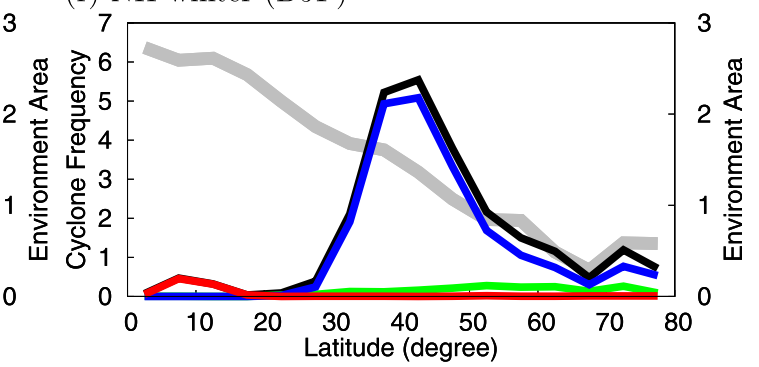

(h) NH spring (MAM)

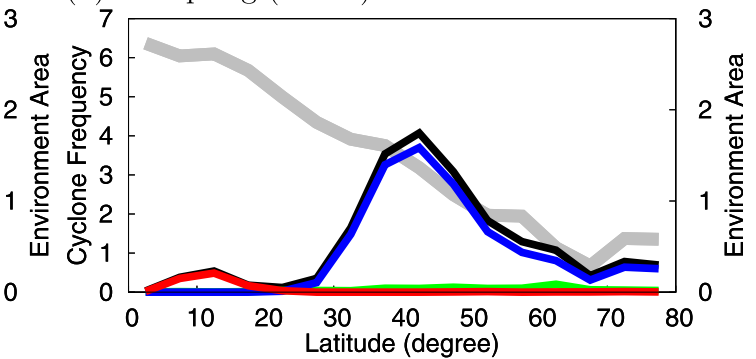

FIG. 5. Cyclone frequencies and environment area in the latitudinal coordinate for (a) $\mathrm{SH}$ summer, (b) NH summer, (c) SH autumn, (d) NH autumn, (e) SH winter, (f) NH winter, (g) SH spring, and (h) NH spring. Thin curves indicate the cyclone frequencies (events day ${ }^{-1}$ range $^{-1}$ ) scaled in the left axis for total cyclones (black), TCs (red), ECs (blue), and HCs (green). Thick gray curve indicates the environment area $\left(10^{6} \mathrm{~km}^{2} \mathrm{day}^{-1} \mathrm{range}^{-1}\right)$ scaled in the right axis.

dynamics are very sensitive to the change in potential intensity (Fig. 3b).

To elucidate the relation between the EPS distribution and geographical distribution, Fig. 7a shows the latitudinal location versus potential intensity for cyclones and environment area. The TCs occur in the low latitudes and in the region with high potential intensity (see also Figs. 1a and 2a), which results in the high TC frequency at high potential intensity in Fig. 6a. On the other hand, the ECs occur in the high latitudes and in the region with low potential intensity (see also Figs. 1a and 2c), which results in the high EC frequency at low potential intensity in Fig. 6a. The large environment area exceeding $500 \times 10^{6} \mathrm{~km}^{2} \mathrm{day}^{-1}$ range ${ }^{-1}$ occurs in the region with high potential intensity $\left(70-80 \mathrm{~m} \mathrm{~s}^{-1}\right)$ in the tropics $\left(0^{\circ}-20^{\circ} \mathrm{S}\right)$, with intermediate potential intensity $\left(20-50 \mathrm{~m} \mathrm{~s}^{-1}\right)$ in the subtropics $\left(20^{\circ}-30^{\circ} \mathrm{S}\right)$, and low potential intensity $\left(0-10 \mathrm{~m} \mathrm{~s}^{-1}\right)$ in the extratropics $\left(30^{\circ} \mathrm{S}\right.$ or 
TABLE 2. The total numbers of TCs, ECs, and HCs for four seasons in $\mathrm{SH}$ and $\mathrm{NH}$.

\begin{tabular}{lrcc}
\hline \hline $\begin{array}{c}\text { Hemisphere and } \\
\text { season }\end{array}$ & TC & EC & HC \\
\hline SH summer (DJF) & 856 & 3510 & 438 \\
NH summer (JJA) & 1167 & 2243 & 169 \\
SH autumn (MAM) & 471 & 5202 & 756 \\
NH autumn (SON) & 1376 & 4192 & 441 \\
SH winter (JJA) & 33 & 6173 & 656 \\
NH winter (DJF) & 173 & 4785 & 385 \\
SH spring (SON) & 97 & 4787 & 487 \\
NH spring (MAM) & 199 & 4343 & 221 \\
\hline
\end{tabular}

higher latitudes). Since the maximum of environment area at each latitude shifts rapidly from high potential intensity in the tropics to low potential intensity in the extratropics, the environment area at the intermediate potential intensity in Fig. 6a is smaller than that at the high and low potential intensity [see also the relation between the environmental parameter (ENV) in Fig. 3a and AREA, indicating environment area, in Fig. 3c].

Figure $6 \mathrm{~b}$ shows the cyclone frequencies and environment area in the EPS of baroclinicity. The total cyclone frequency has a bimodal distribution with the peaks around 0.1 and 0.4 day $^{-1}$ : the former peak is associated with TCs, whereas the latter is associated with
ECs. The minimum of the total cyclone frequency occurs around intermediate baroclinicity $\left(\sim 0.2\right.$ day $\left.^{-1}\right)$, which is frequently observed in the subtropics (Fig. 7b). This characteristic indicates that the baroclinicity is another essential parameter. As the environment area shows a weakly bimodal distribution, it partly causes the bimodal distribution of the cyclone frequency, which supports scenario A (Figs. 3a,c). However, since the bimodal distribution of the environment area is not sharp enough to explain the bimodal distribution of the cyclone frequency again, the bimodal distribution of the cyclone frequency should also be attributed to the sensitivity of cyclone dynamics to the baroclinicity, which supports scenario B (Figs. 3b,d).

While potential intensity and baroclinicity are essential parameters for determining the cyclone types as shown above, other variables may enhance or suppress the cyclone development and modulate the geographical distribution of cyclones. Figure $6 \mathrm{c}$ shows the EPS of relative humidity at $600 \mathrm{hPa}$. The total cyclone frequency (black curve) is negligible in the region with less than $20 \%$ humidity, although the environment area (gray curve) is not small there. This indicates that dry environments are unfavorable for cyclone development. On the other hand, cyclones rarely develop in the region with more than $70 \%$ humidity, where the environment (a)

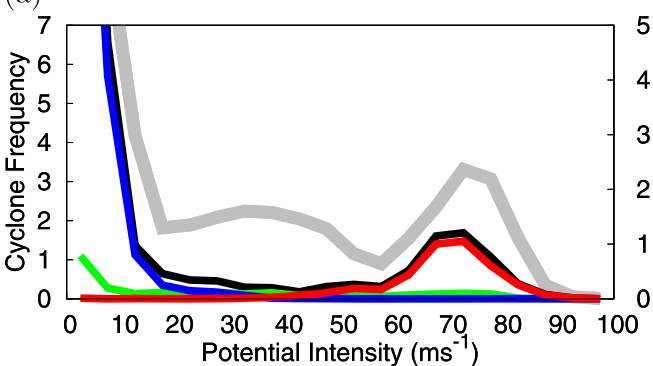

(c)

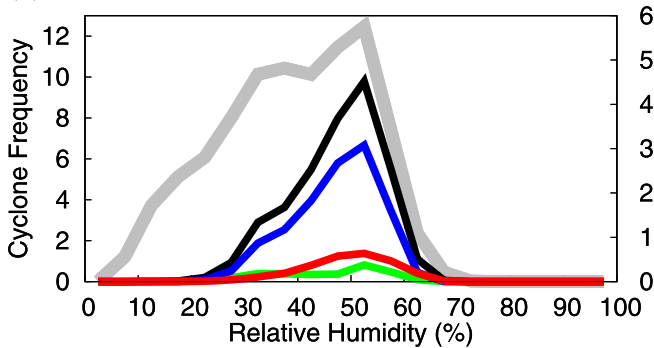

(b)

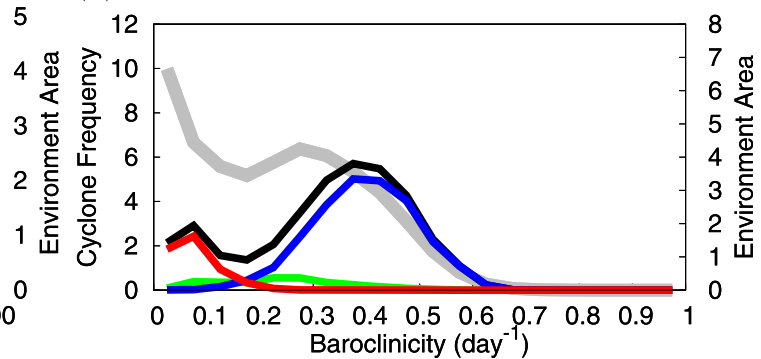

(d)

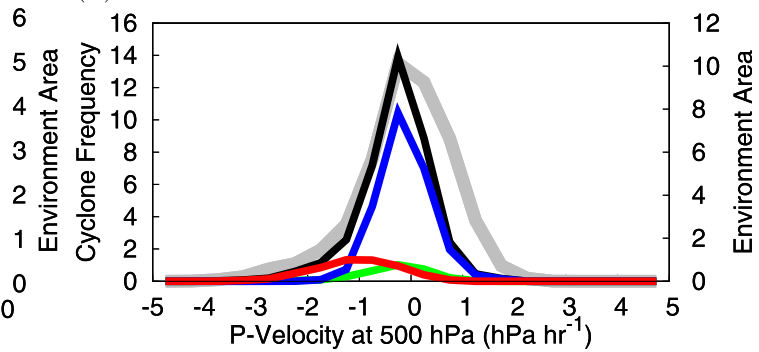

FIG. 6. Cyclone frequency and environment area in the EPS for SH summer. The horizontal axes are (a) potential intensity $\left(\mathrm{m} \mathrm{s}^{-1}\right)$, (b) baroclinicity $\left(\right.$ day $\left.^{-1}\right),(\mathrm{c})$ relative humidity at $600 \mathrm{hPa}(\%)$, and (d) pressure vertical velocity at $500 \mathrm{hPa}\left(\mathrm{hPa} \mathrm{h}^{-1}\right)$. Thin curves indicate the cyclone frequencies (events day ${ }^{-1} \mathrm{range}^{-1}$ ) scaled in the left axis for total cyclones (black), TCs (red), ECs (blue), and HCs (green). Thick gray curve indicates the environment area $\left(10^{6} \mathrm{~km}^{2} \mathrm{day}^{-1}\right.$ range $\left.{ }^{-1}\right)$ scaled in the right axis. In (a), some peaks for the bin $0-5 \mathrm{~m} \mathrm{~s}^{-1}$ are out of the range of the vertical axes: the total cyclone frequency is 20.7 in the left axis, the EC frequency is 17.7 in the left axis, and the environment area is 11.9 in the right axis. 
(a)

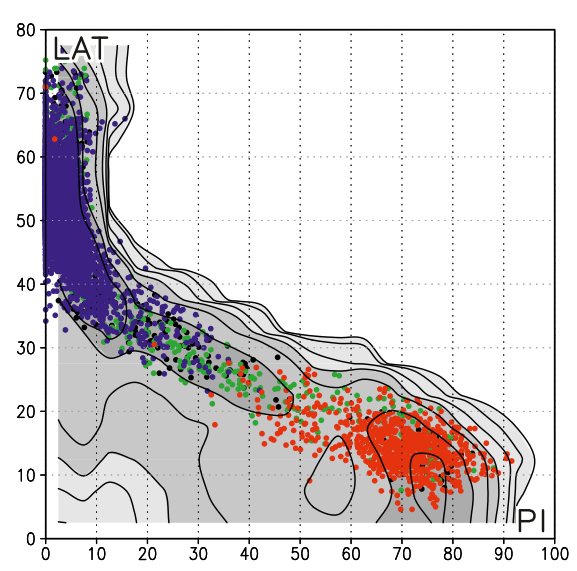

(c)

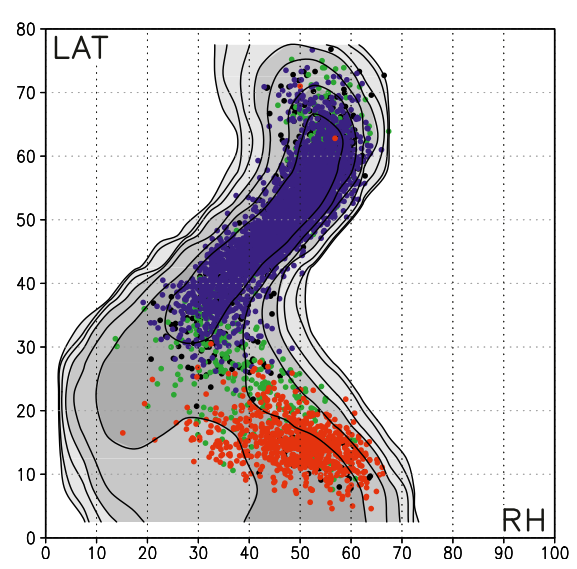

(b)

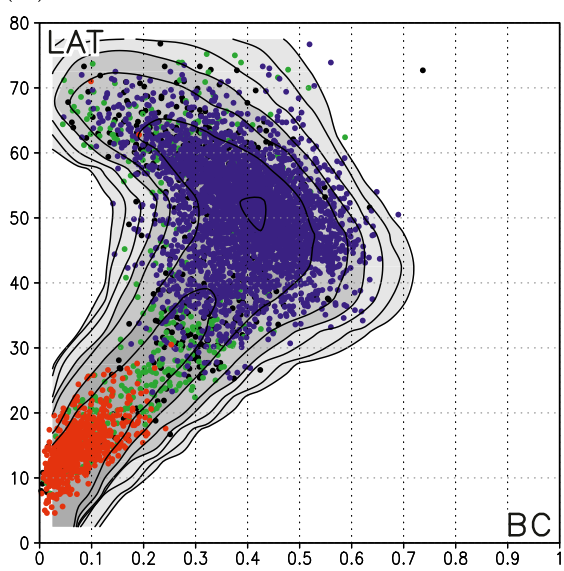

(d)

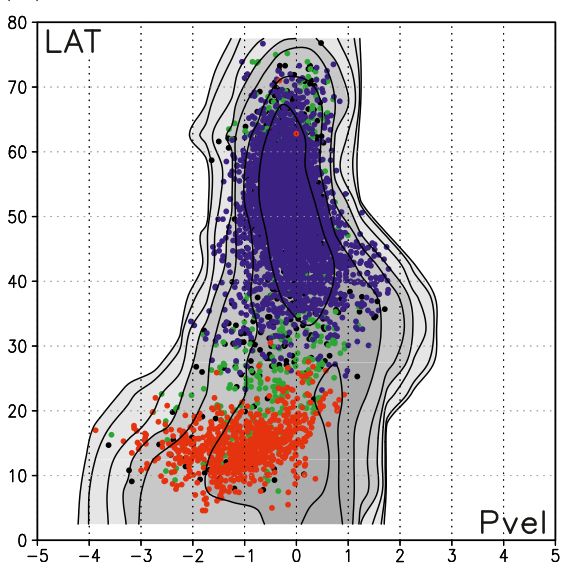

FIG. 7. The 2D EPS for SH summer with latitude $\left(^{\circ}\right)$ and (a) potential intensity $\left(\mathrm{m} \mathrm{s}^{-1}\right)$, (b) baroclinicity $\left(\right.$ day $\left.^{-1}\right),(\mathrm{c})$ relative humidity at $600 \mathrm{hPa}(\%)$, and (d) pressure vertical velocity at $500 \mathrm{hPa}\left(\mathrm{hPa} \mathrm{h}^{-1}\right)$. Contours indicate environment area of 10, 20, 50, 100, 200, 500, and $1000 \times 10^{6} \mathrm{~km}^{2} \mathrm{day}^{-1}$ range $^{-1}$, where the light, intermediate, and dark gray shadings indicate environment area exceeding 10,100, and 500, respectively. Plots indicate TCs (red), ECs (blue), HCs (green), and ill-defined cyclones (gray).

area is small. This simply means that there are few areas where cyclones can develop. Note that the relative humidity rarely exceeds $70 \%$, even at the location of TC development, because the high humidity at the center of cyclones is filtered out in the environmental field as described in section 2c, which is consistent with Fig. 42 in Gray (1975). The distribution of the cyclone frequency shifts to the high humidity region compared to the distribution of the environment area, which indicates that cyclones tend to develop in the region with high humidity. Since low humidity frequently occurs around $20^{\circ}-30^{\circ} \mathrm{S}$ (Fig. $7 \mathrm{c}$ ), the dry environment in the subtropics may suppress the cyclone development, which enhances the bimodal distribution of cyclone development. It should also be noted that the cyclone frequency in the EPS of relative humidity shows a unimodal distribution with little separation between TCs and ECs because both types of cyclones develop in the high humidity environment. Therefore, relative humidity is not an essential parameter for determining cyclone types, even though it may influence the cyclone development.

Figure 6d shows the EPS of pressure vertical velocity at $500 \mathrm{hPa}$. The total cyclone frequency shows only a unimodal distribution with a peak around $0 \mathrm{hPah}^{-1}$, which indicates that the vertical velocity is not essential for the geographically bimodal distribution. However, the distribution of cyclone frequency shifts to the region with negative pressure vertical velocity compared to the environment area, which indicates that cyclones develop more frequently in the environments with ascending motion. In particular, the majority of the TC frequency occurs in the region with negative pressure vertical velocity. Since 
(a)

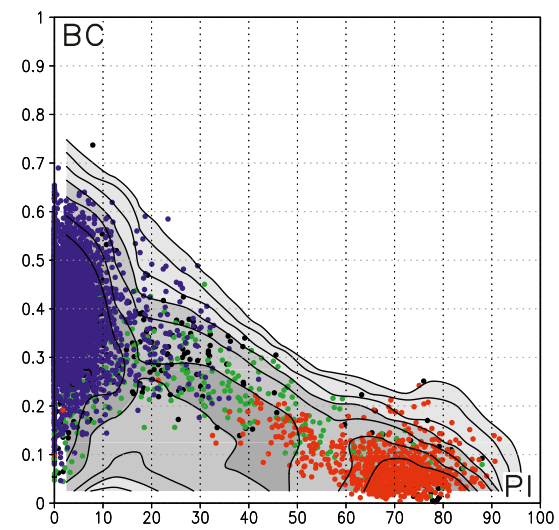

(b)

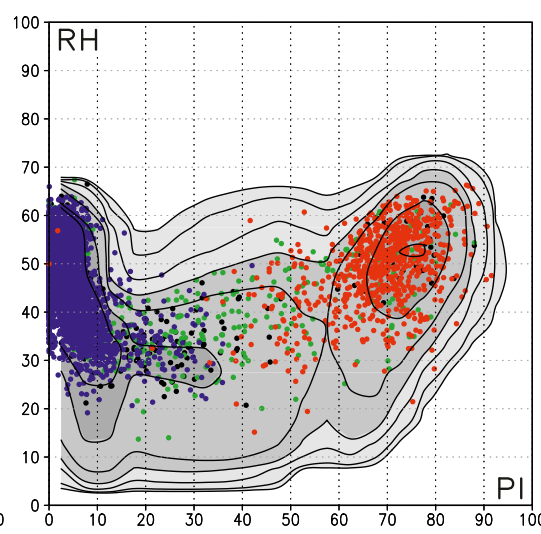

(c)

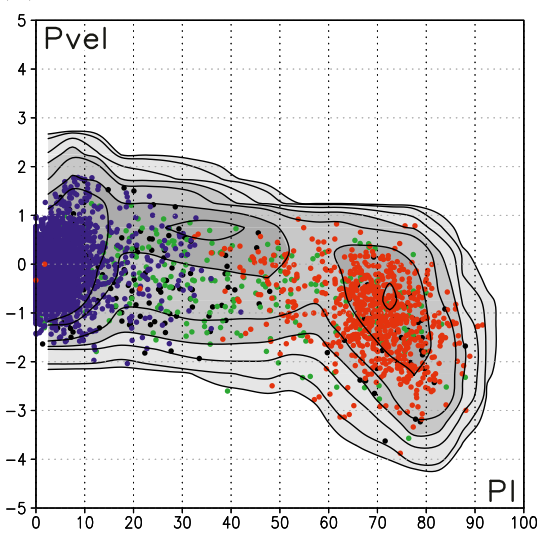

FIG. 8. The 2D EPS for SH summer for (a) potential intensity $\left(\mathrm{m} \mathrm{s}^{-1}\right.$ ) and baroclinicity (day $\left.{ }^{-1}\right)$, (b) potential intensity and relative humidity at $600 \mathrm{hPa}(\%)$, and (c) potential intensity and pressure vertical velocity at $\left.500 \mathrm{hPa}(\mathrm{hPa} \mathrm{h})^{-1}\right)$. Contours indicate environment area of 10, 20,50,100,200,500, and $1000 \times 10^{6} \mathrm{~km}^{2} \mathrm{day}^{-1}$ range $^{-1}$, where the light, intermediate, and dark gray shadings indicate environment area exceeding 10, 100, and 500, respectively. Plots indicate TCs (red), ECs (blue), HCs (green), and ill-defined cyclones (gray).

Fig. 7d shows that positive pressure vertical velocity frequently occurs around $30^{\circ} \mathrm{S}$, the descending motion in the subtropics may suppress the cyclone development, which enhances the geographically bimodal distribution of cyclone development.

\section{b. Relationship between environmental parameters}

The previous section demonstrated that potential intensity and baroclinicity are essential environmental parameters for determining the cyclone types of TCs and ECs (Figs. 6a,b), which can cause the geographically bimodal distribution. Relative humidity and vertical velocity may also enhance the contrast of cyclone development between the tropics (extratropics) and subtropics (Figs. 6c,d and 7c, d). To understand how the combinations of the environmental parameters affect cyclone development, this section makes use of two-dimensional (2D) EPS diagrams, in which an environmental parameter is chosen as a horizontal axis whereas another is chosen as a vertical axis.

Figure 8a shows a 2D EPS diagram of potential intensity and baroclinicity. A region of high environment area (dark shading) extends from the lower right to the upper left, which corresponds to the environment from tropics to extratropics (Figs. 2a,c). Within this inverse distribution of high environment area, TCs and ECs are concentrated near both ends, whereas cyclones are inactive in the intermediate region with $20-50 \mathrm{~m} \mathrm{~s}^{-1}$ potential intensity and $\sim 0.2$ day $^{-1}$ baroclinicity. Because the environment area in the intermediate region is smaller than that in the lower right and upper left regions, the low environment area in the intermediate region partly explains the inactive cyclone development in the subtropics, which supports scenario A (Fig. 3c). However, the number of cyclones in the intermediate region seems to be too small to be explained by the environment area.

Figure 9a shows the "cyclone efficiency" per unit area in the 2D EPS diagram (color contours) defined by the ratio of cyclone frequency to environment area. The cyclone efficiency is useful to assess scenario $B$ because the cyclone frequency is normalized by the environment area. The cyclone efficiency is apparently small in the intermediate region. Thus, the low cyclone frequency in the intermediate region is attributed to the sensitivity of cyclone dynamics to the environmental parameter, which supports scenario B (Fig. 3d). While the result of the 2D EPS analysis is consistent with that of the one-dimensional (1D) EPS analysis (Figs. 6a,b), it also provides further insight into the relationship between two environmental parameters. For example, the environment area vanishes in the upper right region (high potential intensity and high baroclinicity). Therefore, ECs usually develop in the region with low potential intensity as seen in Fig. 6a, not because ECs prefer small potential intensity, but because the large baroclinicity favorable for EC development occurs only in the region with low potential intensity. A similar explanation is possible as to why TCs develop in the region of small baroclinicity. It is also possible that TC development is suppressed by strong vertical wind shear associated with large baroclinicity. In summary, scenarios A and B (Figs. $3 \mathrm{c}, \mathrm{d})$ occur in the 2D EPS of PI and BC, rather than in the 1D EPS of each parameter independently.

Figure $8 \mathrm{~b}$ shows the 2D EPS of potential intensity and relative humidity. TCs and ECs are concentrated in the regions with high and low potential intensity, respectively. In these regions, TCs and ECs occur in the high humidity region, which means that cyclones prefer 
(a)

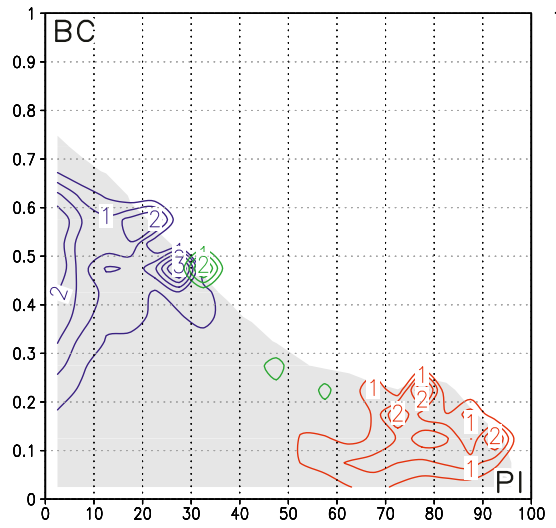

(b)

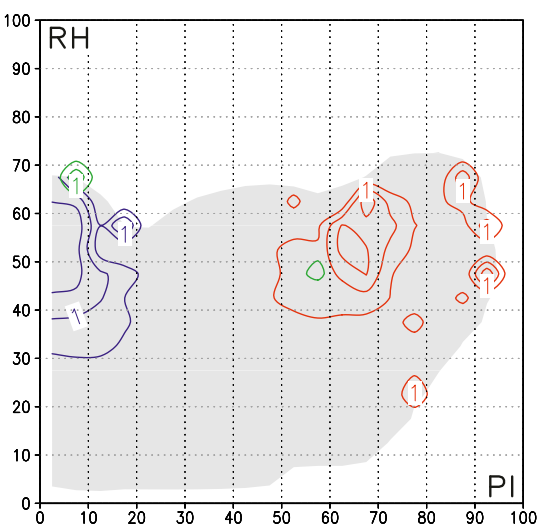

(c)

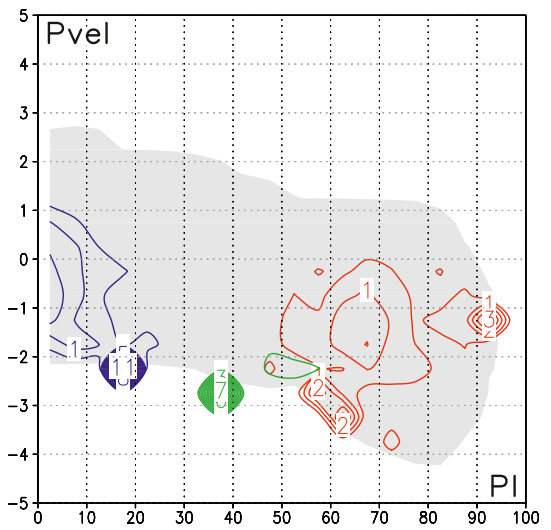

FIG. 9. The cyclone efficiency (contour interval is $0.5 \times 10^{-8}$ events $\mathrm{km}^{-2}$ ) in $2 \mathrm{D}$ EPS for SH summer for (a) Potential intensity (m s${ }^{-1}$ ) and baroclinicity $\left(\right.$ day $\left.^{-1}\right)$, (b) potential intensity and relative humidity at $600 \mathrm{hPa}(\%)$, and (c) potential intensity and pressure vertical velocity $\left(\mathrm{hPa} \mathrm{h}^{-1}\right)$. Contour colors indicate TCs (red), ECs (blue) and HCs (green). The efficiency is calculated only in the region with the environment area exceeding $10 \times 10^{6} \mathrm{~km}^{2} \mathrm{day}^{-1} \mathrm{range}^{-1}$ (shading) because the number of samples is small in the region with small environment area.

the humid region, as shown in the 1D EPS of relative humidity (Fig. 6c). As relative humidity is low in the region with intermediate potential intensity that corresponds to the subtropics (see also Figs. 2a,e and 7a,c), the relative humidity may enhance the contrast of TC development between the tropics and subtropics and that of EC development between the extratropics and subtropics. On the other hand, since Fig. 9b shows that the cyclone efficiency still has peaks of TCs and ECs along the coordinate of potential intensity at a fixed value of relative humidity (e.g., $50 \%$ ), the cyclone dynamics to the potential intensity is sensitive even in the absence of the influence of relative humidity. In a similar manner, the descending motion in the subtropics (Figs. $2 \mathrm{~g}$ and $7 \mathrm{~d}$ ) seems to be only secondary for causing the geographically bimodal distribution of cyclone development (Figs. 8c and 9c), although it may partly suppress the cyclone development in the subtropics.

\section{c. Comparison between hemispheres and seasons}

The geographical distributions of cyclones are different between the SH and the NH (Fig. 1), and this is likely to reflect the difference in environmental fields between the hemispheres (Fig. 2). In this section, the EPS analysis is used to examine whether the relationships between the cyclones and their environmental fields are similar or not between the hemispheres and the seasons. This section mainly focuses on the NH summer, which is accompanied by both TCs and ECs just as the SH summer, but shows less uniform distribution in the longitudinal direction than the $\mathrm{SH}$ summer.

Figure 10 shows the cyclone frequency and environment area in the 1D EPS for the NH summer. In the EPS of potential intensity (Fig. 10a), the total cyclone frequency shows a sharp bimodal distribution, whereas the environment area is characterized by weak bimodal distribution. As shown in the SH summer (Fig. 6a), these characteristics indicate that the bimodal distribution of cyclones are attributed to both the rapid changes in the environmental fields around the subtropics (scenario A) and sensitivity of cyclones to potential intensity (scenario B). In the EPS of baroclinicity (Fig. 10b), the total cyclone frequency also shows a bimodal distribution, although the environment area monotonically decreases with increasing baroclinicity; the monotonic decrease of the environment area is associated with the disappearance of the second peak around $0.3 \mathrm{day}^{-1}$, which seems to result from the smaller oceans in the mid- and high latitudes in the $\mathrm{NH}$ rather than in the SH. (Figs. 2c,d). These results indicate that the bimodal distribution of cyclones is explained only by the sensitivity of cyclones to baroclinicity (scenario B). The EPSs of relative humidity and vertical velocity (Figs. 10c,d) show that cyclones frequently develop in the regions with high humidity and updraft. Thus, the results for the NH summer are similar to those for the SH summer, except that scenario A is not important for baroclinicity. Since scenario B is important for both $\mathrm{NH}$ and $\mathrm{SH}$ summer, the sensitivity of cyclone dynamics to the environmental field seems to be a robust characteristic.

Figure 11 shows the 2D EPSs for the NH summer. In the EPS of potential intensity and baroclinicity (Fig. 11a), a region of large environment area extends from the lower right to the upper left, and TCs and ECs are concentrated near both ends of the region. This characteristic is similar to that in the SH summer. Both the EPS of potential intensity and relative humidity (Fig. 11b) and that of 
(a)

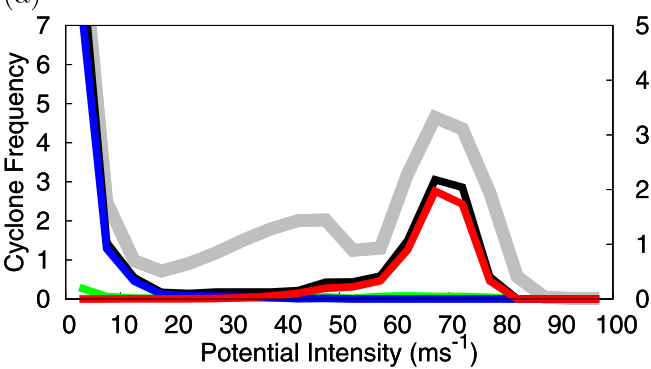

(c)

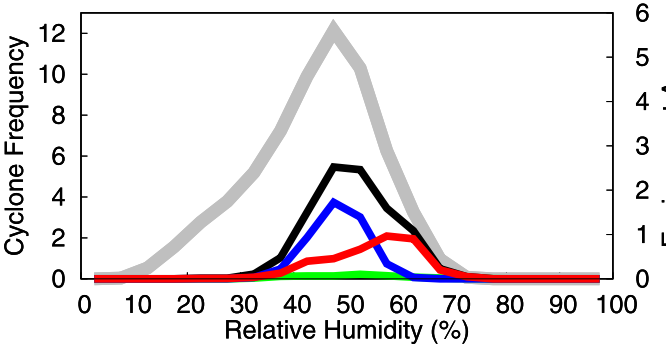

(b)

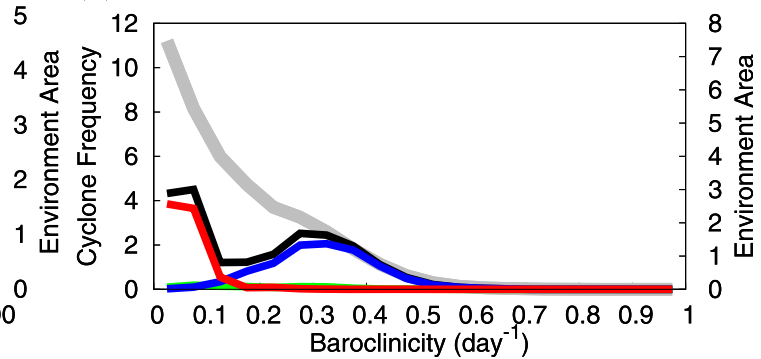

(d)

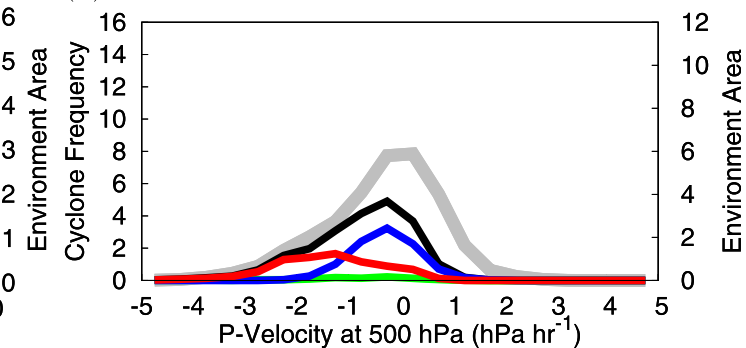

FIG. 10. As in Fig. 6, but for NH summer, where in (a) some peaks for the bin $0-5 \mathrm{~m} \mathrm{~s}^{-1}$ are out of the range of the vertical axes: the total cyclone frequency is 9.3 in the left axis, the EC frequency is 8.0 in the left axis, and the environment area is 7.1 in the right axis.

potential intensity and vertical velocity (Fig. 11c) in the $\mathrm{NH}$ summer are also similar to those in the SH summer. Therefore, the relationships between cyclones and their environmental field are almost the same for both hemispheres when they are seen in the EPS distributions, although their distributions in the geographical space are different.

Figure 12 shows the 2D EPS diagrams of potential intensity and baroclinicity for the other seasons in both hemispheres. The distribution of cyclones and environment area in the autumn (Figs. 12a,b) is similar to that in the summer (Figs. 8a, 11a). TCs in the winter and spring seasons are inactive even in the region with high potential intensity
(Figs. 12c-f). This is because the high potential intensity occurs near the equator where planetary vorticity is small and where cyclones hardly develop. Except for the small number of TCs in winter and spring, the distributions of TCs, ECs, and environment area are generally similar regardless of the hemispheres and seasons in the EPS. Note that the environment area is large in the region with large baroclinicity $\left(\sim 1\right.$ day $\left.^{-1}\right)$ in the NH winter (Fig. 12d) because the baroclinicity is enhanced over the western parts of the oceans (not shown), which seem to be attributed to the large horizontal gradient of the sea surface temperature and to the contrast of diabatic heating between continents and oceans (Valdes and Hoskins 1989; Sauliere et al. 2012). (a)

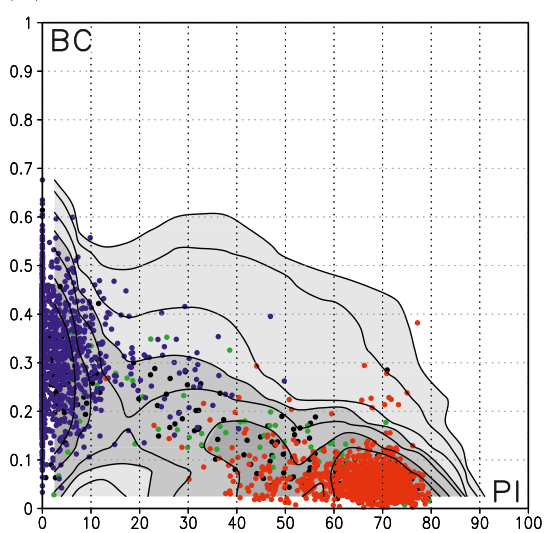

(b)

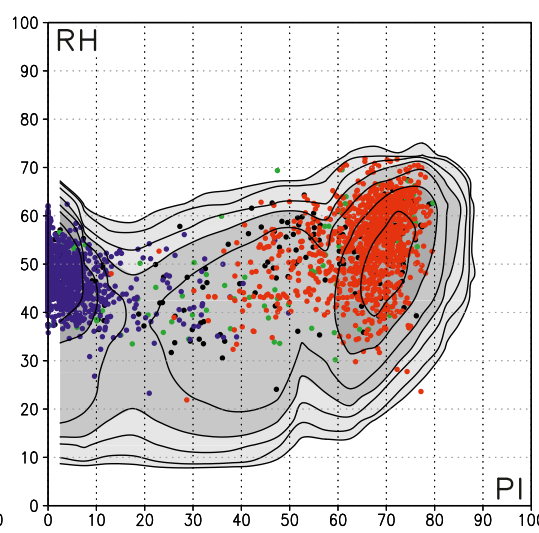

(c)

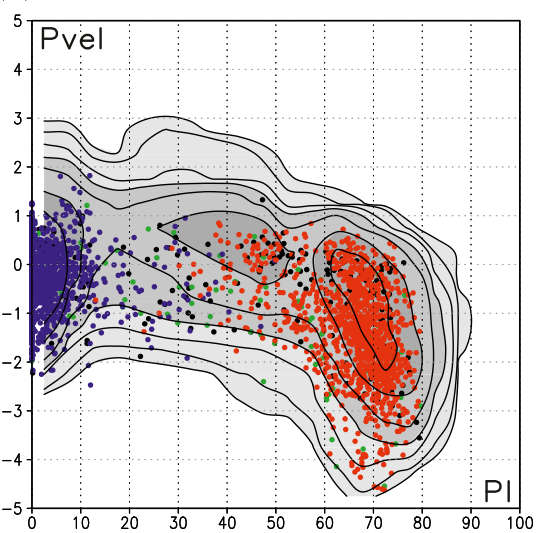

FIG. 11. As in Fig. 8, but for NH summer. 
(a) SH autumn (MAM)

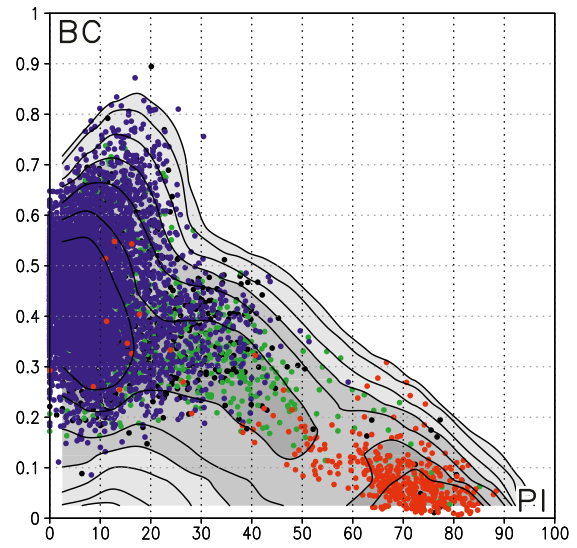

(c) $\mathrm{SH}$ winter (JJA)

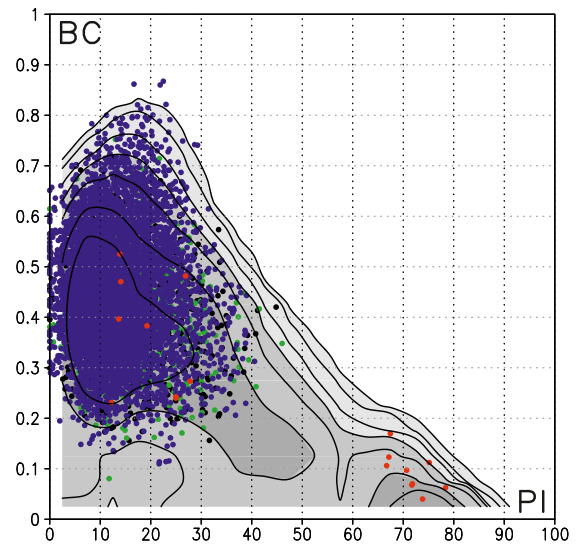

(e) $\mathrm{SH}$ spring (SON)

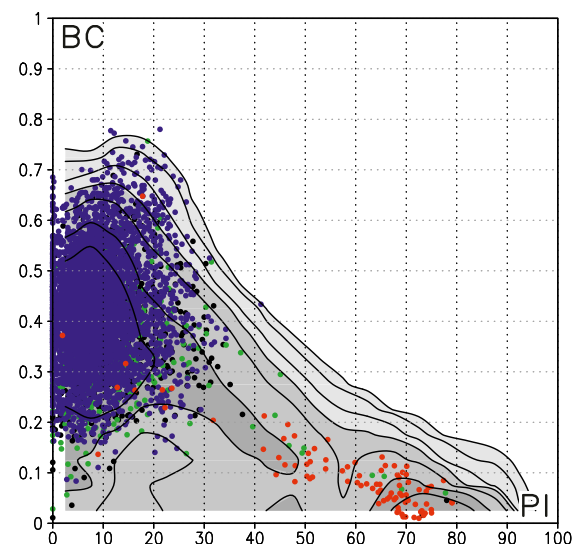

(b) $\mathrm{NH}$ autumn $(\mathrm{SON})$

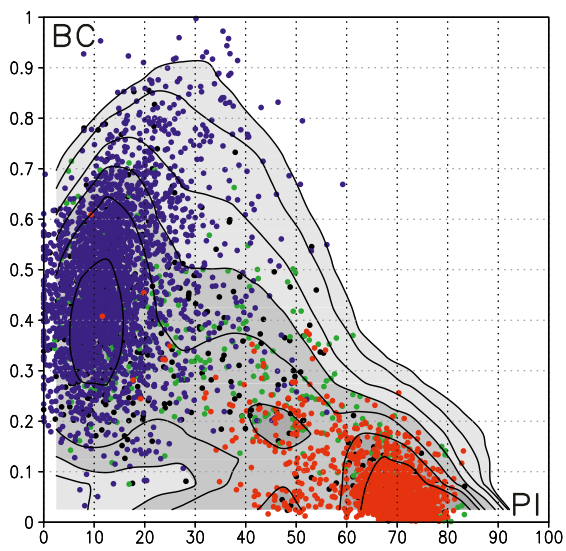

(d) NH winter (DJF)

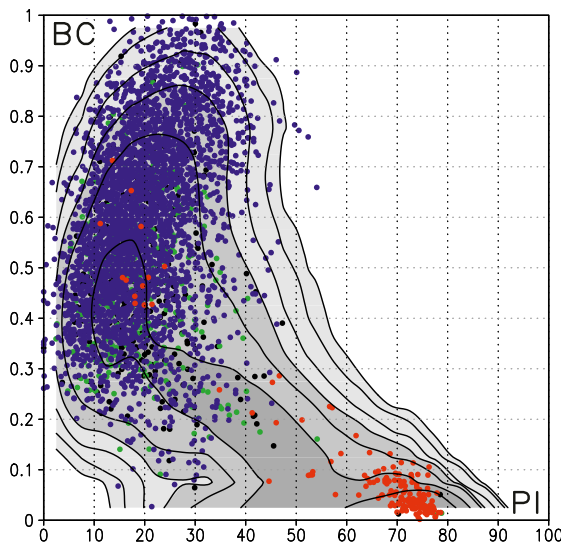

(f) $\mathrm{NH}$ spring (MAM)

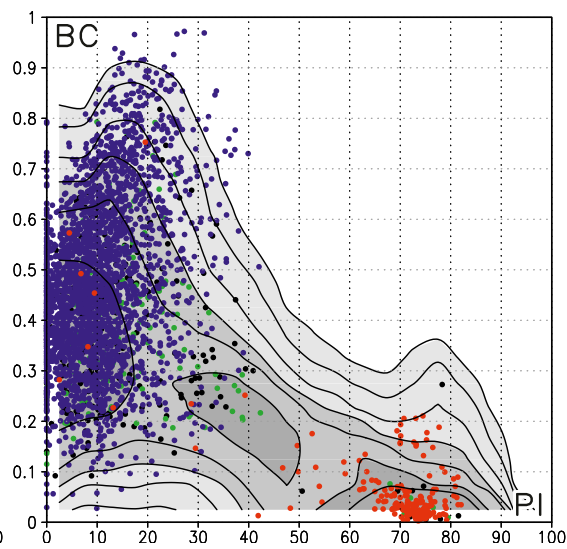

FIG. 12. As in Fig. 8a, but for (a) SH autumn, (b) NH autumn, (c) SH winter, (d) NH winter, (e) SH spring, and (f) NH spring.

\section{Discussion}

\section{a. Interpretation of geographical distribution}

The results of the EPS analysis show the following characteristics of the environmental fields that are responsible for the geographically bimodal distribution of cyclones from the tropics to extratropics. First, in the 1D EPSs of potential intensity (Figs. 6a and 10a) and baroclinicity (Figs. 6b and 10b), the cyclone frequency shows a sharper bimodal distribution than the 
environment area. In the geographical space, these results indicate that the TC (EC) dynamics are sensitive to the change in potential intensity (baroclinicity) around the subtropics. This is also confirmed in the 2D EPS (Fig. $9 \mathrm{a})$, where the cyclone efficiency shows a bimodal distribution. These results support scenario B (Figs. 3b,d). Second, in the 1D EPSs of potential intensity (in both $\mathrm{NH}$ and SH summer) and baroclinicity (only in the SH summer), the environment area shows a weak bimodal distribution. In the geographical space, this means that potential intensity (baroclinicity) rapidly changes around the subtropics, which supports scenario A (Figs. 3a,c). In addition, cyclones are inactive in the region with low humidity and descending motion in the midtroposphere (Figs. 6c,d and 10c,d). In the 2D EPSs, the low humidity and descending motion are frequent in the region with intermediate potential intensity (Figs. 8b,c and 11b,c) and intermediate baroclinicity (not shown), which correspond to the subtropical environment. Therefore, in the geographical space, the humidity and vertical motion may enhance the contrast between the active cyclone development in the tropics (extratropics) and the inactive cyclone development in the subtropics. The subtropical characteristics with inactive cyclone development, low humidity, and subsidence is more remarkable over the eastern parts of the oceans, where the subtropical high pressure system is intensified during the summer season (Hoskins 1996; Miyasaka and Nakamura 2005).

It is worth discussing the distribution of the environment area in the 2D EPS of potential intensity and baroclinicity (Figs. 8a, 11a, and 12). In all the seasons in both hemispheres, the large environment area (shading) extends from the lower right to the upper left. Cyclones are inactive in the region having intermediate potential intensity and intermediate baroclinicity, which corresponds to the subtropics. However, if there were a region with high potential intensity and high baroclinicity between the tropics and extratropics, cyclones might be more active in the subtropical region. Such a symptom is slightly observed in the NH autumn (Fig. 12b), in which the large environment area extends to the region with higher potential intensity and higher baroclinicity than in the other seasons and hemispheres (e.g., compare the magnitude of the environment area at $50 \mathrm{~m} \mathrm{~s}^{-1}$ potential intensity and 0.5 day $^{-1}$ baroclinicity). In fact, there are more cyclones in the subtropics in the NH autumn than in the other seasons and hemispheres (Figs. 1 and 5). In addition to TCs, HCs are active over the North Atlantic during the autumn season, which is consistent with the results of previous studies on subtropical cyclones (Guishard et al. 2009), on the extratropical transitioning of TCs (Hart and Evans 2001), and on the tropical transitioning of extratropical disturbances (Mctaggart-Cowan et al. 2013). In the geographical space for the NH autumn, the region with high potential intensity and the region with high baroclinicity overlap in the subtropics over the western Pacific and western Atlantic (not shown) because of the longitudinal nonuniformity in the NH. It would be worth examining whether the area with high potential intensity and high baroclinicity will increase or decrease under climate changes such as global warming and the Last Glacial Maximum (LGM) and indeed extending this analysis to climate change simulations.

\section{b. Environments and other factors affecting cyclone development}

The present study has assessed the representative environmental parameters shown in Table 1. Potential intensity and baroclinicity are chosen because they are commonly used environmental parameters for TC and EC analysis, respectively (Hoskins and Valdes 1990; Hart and Evans 2001; Bister and Emanuel 2002; Camargo et al. 2007; Yanase and Abe-Ouchi 2010). In a strict sense, the potential intensity based on the wind-induced surface heat exchange (WISHE) mechanism is a concept for steady-state TCs at their peak intensity, not for the growth rate of TC development. Therefore, if there is another parameter more suitable for explaining the cyclone development, it is of interest to use the parameter for the EPS analysis. Because the concept of potential intensity is only available over the ocean, and because the surface conditions are different between land and ocean, the cyclones over the land are not analyzed in the present study. In the future work, we would like to analyze the cyclones over land to obtain a comprehensive understanding of cyclones. Relative humidity and vertical velocity are examined since they are expected to enhance or suppress the cyclone development. In addition to these variables, other environmental parameters such as relative vorticity may also influence cyclone development. If the EPS analysis can reveal important environmental factors affecting cyclone types and their development comprehensively, a more sophisticated environmental index, which consists of several environmental parameters such as a genesis potential index (Emanuel and Nolan 2004; Camargo et al. 2007), may be developed. Since some of the environmental parameters may depend on each other, the correlation among environmental fields should also be examined. For example, relative humidity has a high correlation with vertical velocity in the midtroposphere (not shown), which indicates that they can be consolidated to one variable. The correlation between environmental fields will be assessed in detail using the 2D EPS analysis in a forthcoming paper.

The importance of the environmental fields for cyclone development is based on the development mechanisms 
(a) $\mathrm{SH}$ summer

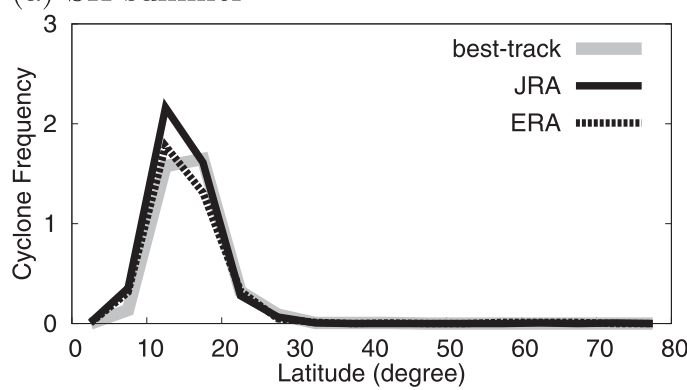

(b) NH summer

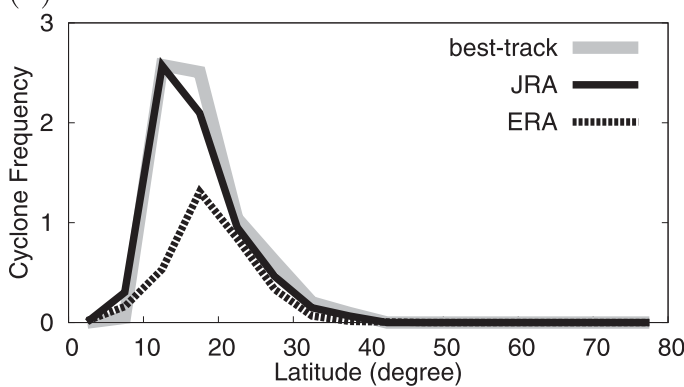

FIG. 13. The TC frequencies in the latitude coordinate obtained from the IBTrACS (gray), the JRA-25/JCDAS (solid black), and the ERA-Interim (dashed black) for (a) SH and (b) NH summer.

of cyclones such as a positive feedback between a vortex and diabatic processes for TCs (Ooyama 1969; Rotunno and Emanuel 1987; Smith 1997) and baroclinic instability for ECs (Eady 1949; Charney 1949; Hoskins 1976). However, in contrast to the simplified atmosphere assumed in the theoretical studies, cyclone developments in the real atmosphere are affected by many other factors. First, a cyclone may develop via different mechanisms during its lifetime. For example, after TCs develop through diabatic processes in the low latitudes, some of them may transition into an EC and redevelop through baroclinic instability (an extratropical transition of a TC; Hart and Evans 2001; Kitabatake 2008, 2011). Second, cyclone development may be modulated by other disturbances: upper-tropospheric disturbances (Dveson et al. 2002; Jones et al. 2003; Hart et al. 2006; Mctaggart-Cowan et al. 2013) and tropical waves (Frank and Roundy 2006; Yanase et al. 2010). These disturbances are also filtered out in the present study because their time scales are much shorter than the environmental fields considered here. For the comprehensive understanding of cyclone development, case analysis of individual cyclones and composite analysis of particular cyclones are also necessary. In spite of the modulations by these factors, cyclones still develop in the limited regions in the EPSs (Figs. 8, 11, and 12). This indicates that the environmental fields play essential roles for controlling the cyclone development in the real atmosphere. The variation of the cyclones in the EPS diagram reflects a balance between the environmental influence and the other factors in the development of cyclones.

\section{c. Other datasets}

It is important to evaluate to what extent a reanalysis dataset can represent the characteristics of cyclones (Kitabatake 2010; Hodges et al. 2011; Schenkel and Hart 2012). Figure 13 compares the latitudinal distribution of TC frequency between the IBTrACS best track, the JRA25/JCDAS reanalysis, and the ERA-Interim reanalysis.
Developing stages of TCs in the best-track data are chosen using the same threshold of growth rate as in the reanalysis datasets $\left(0.1 \mathrm{day}^{-1}\right)$ except that the wind speed of $34 \mathrm{kt}\left(1 \mathrm{kt} \approx 0.5 \mathrm{~m} \mathrm{~s}^{-1}\right)$ is used instead of vorticity as the threshold of intensity. The latitudinal distribution for the JRA-25/JCDAS is nearly the same as that for the besttrack data. Schenkel and Hart (2012) confirmed that the JRA-25 represents the locations and intensities of TCs more realistically than the other reanalysis datasets, although the horizontal resolution of the JRA-25 was the lowest among the datasets. The realistic representation of TCs in the JRA-25 is attributed to the TC wind profile retrievals, which are preferable for the analysis of TC distribution.

Figure 14 shows the cyclone plots in the 2D EPS of potential intensity and baroclinicity for the $\mathrm{SH}$ and $\mathrm{NH}$ summers that are obtained from the ERA-Interim data. The distribution of cyclones is similar between the JRA25/JCDAS and ERA-Interim datasets: TCs (ECs) are concentrated in the lower right (upper left) region. Therefore, the characteristics described in section 3 appear to be robust in a qualitative sense, although there are some quantitative differences between the datasets. If reanalysis datasets can represent the intensity and structure more realistically, it will be possible to discuss the difference of growth rates of cyclones and detailed classification of cyclone types including mesoscale cyclones. The reanalysis datasets for longer periods will also provide more robust understanding of the statistics of cyclones. These analyses will be conducted using a new reanalysis dataset such as the Japanese 55-yr Reanalysis (JRA-55; Ebita et al. 2011) in the future.

\section{Summary}

To understand the geographically bimodal distribution of cyclone development with the two peaks in the tropics and the extratropics, the direct relationship between cyclones and their environments are analyzed using the 
(a) SH summer

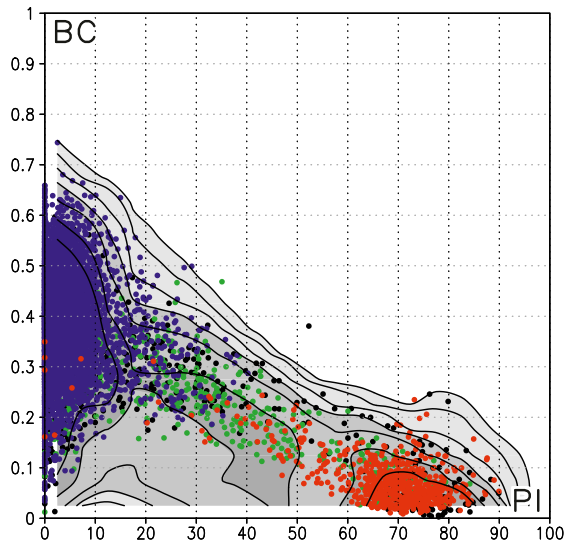

(b) NH summer

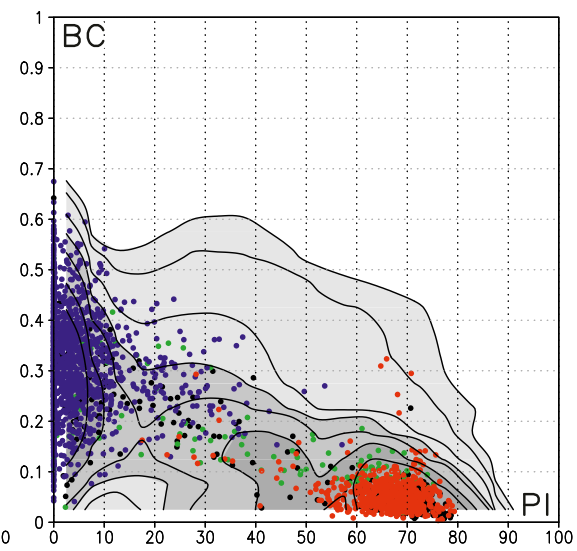

FIG. 14. As in Figs. 8a and 11a, but for cyclone plots obtained from the ERA-Interim for (a) $\mathrm{SH}$ and (b) NH summer. The environment area (gray shading) for the JRA-25/JCDAS is also shown for reference.

EPS analysis. The cyclone frequency in the EPS provides the information on the number of cyclones observed at each environmental value. In addition, the environment area provides the information on the area size of each environmental value, which is important because a larger area gives more chance for cyclone development. The EPS analysis demonstrated that the geographically bimodal distribution is attributed to the high sensitivity of TC (EC) dynamics to the change in the potential intensity (baroclinicity) around the subtropics (scenario B; Figs. $3 \mathrm{~b}, \mathrm{~d})$. The bimodal distribution is also partly attributed to the rapid change in the potential intensity (baroclinicity) around the subtropics (scenario A; Figs. 3a,c). Furthermore, relative humidity and vertical velocity seem to play secondary roles to enhance the geographical contrast between tropics (extratropics) and subtropics. The subtropical characteristics with inactive cyclone development, low humidity, and subsidence are more remarkable over the eastern parts of the oceans. The other variables such as relative vorticity and vertical shear will be examined in detail in a forthcoming paper.

The relationships between cyclones and their environments in the EPS are similar between the hemispheres and seasons, whereas the geographical distributions of cyclones and environmental fields are different between the hemispheres. This confirms that environmental fields play essential roles for controlling cyclone types and their development. Considering this result, the EPS analysis can be used to evaluate the performance of a numerical model for representing the cyclone dynamics in present climate simulations. It is also of interest to examine the relationship between cyclones and their environments in the future, past, and aquaplanet simulations to explore a wide range of parameter space.
The present study mainly assesses TCs and ECs during the summer and autumn seasons to understand the geographical bimodal distribution of cyclone development. It is also important to analyze the environmental fields of ECs over both oceans and lands in other seasons and HCs in detail. Since the EPS can deal with the environmental fields on various time scales, it can be used to analyze mesoscale cyclones such as polar lows (Rasmussen and Turner 2003), medicanes (Fita et al. 2007), baiu frontal depressions (Tochimoto and Kawano 2012), and subsynoptic-scale subtropical lows (Ogura et al.2005). The EPS analysis is a promising approach to understanding the environmental fields of various types of cyclones.

Whereas the EPS analysis is useful to describe the relationship between cyclones and their environments for a given climate, the statistical approach has some inherent limitations. First, a given climate cannot cover the entire parameter space; for example, what are the cyclone dynamics in the region of high potential intensity and high baroclinicity? Second, the environmental field such as relative humidity may be modified by cyclone activity itself, which should be carefully discussed in terms of a causal relationship. Third, a specific region in the EPS of a limited number of parameters still contains various factors including the difference in the other environmental parameters and interactions with other disturbances. Therefore, idealized numerical experiments may play a complementary role because it can examine the pure cyclone development in a prescribed genuine environment (Yanase and Niino 2005, 2007). In particular, it is useful to separate the influence of individual environmental factors and to examine the cyclone development in an extreme environment. 
Acknowledgments. We acknowledge helpful comments by Drs. P. L. Vidale, M. Roberts, J. Strachan, R. E. Hart, Y. Ogura, H. Tsuguchi, and M. Zahn. The atmosphere and ocean datasets made use of JRA-25/ JCDAS, ERA-Interim, and NOAA OISST. The besttrack data were obtained from the IBTrACS website. Potential intensity was calculated using the FORTRAN program from the website of Dr. K. Emanuel. This research was supported by JSPS KAKENHI Grants 23740349, 24244074, and 25106703 and by the Overseas Internship Program for Outstanding Young Earth and Planetary Researchers.

\section{REFERENCES}

Bister, M., and K. A. Emanuel, 2002: Low frequency variability of tropical cyclone potential intensity 1 . Interannual to interdecadal variability. J. Geophys. Res., 107, 4801, doi:10.1029/ 2001JD000776.

Camargo, S. J., K. A. Emanuel, and A. H. Sobel, 2007: Use of a genesis potential index to diagnose ENSO effects on tropical cyclone genesis. J. Climate, 20, 4819-4834.

_ M. C. Wheeler, and A. H. Sobel, 2009: Diagnosis of the MJO modulation of tropical cyclogenesis using an empirical index. J. Atmos. Sci., 66, 3061-3074.

Charney, J. G., 1949: The dynamics of long waves in a baroclinic westerly current. J. Meteor., 4, 135-162.

Davis, C. A., and L. F. Bosart, 2004: The TT problem: Forecasting the tropical transition of cyclones. Bull. Amer. Meteor. Soc., 85, 1657-1662.

Dveson, A. C., K. A. Browning, and T. D. Hewson, 2002: A classification of FASTEX cyclones using a height-attributable quasi-geostrophic vertical-motion diagnostic. Quart. J. Roy. Meteor. Soc., 128, 93-117.

Eady, E. T., 1949: Long waves and cyclone waves. Tellus, 1, 33-52.

Ebita, A., and Coauthors, 2011: The Japanese 55-year Reanalysis "JRA-55": An interim report. SOLA, 7, 149-152.

Emanuel, K. A., 1986: An air-sea interaction theory for tropical cyclones. Part I: Steady-state maintenance. J. Atmos. Sci., 43, 585-604.

— , and D. S. Nolan, 2004: Tropical cyclone activity and global climate. Proc. 26th Conf. on Hurricanes and Tropical Meteorology, Miami, FL, Amer. Meteor. Soc., 240-241.

Evans, J. L., and M. P. Guishard, 2009: Atlantic subtropical storms. Part I: Diagnostic criteria and composite analysis. Mon. Wea. Rev., 137, 2065-2080.

_- and A. Braun, 2012: A climatology of subtropical cyclones in the South Atlantic. J. Climate, 25, 7328-7340.

Fita, L., R. Romero, A. Luque, K. Emanuel, and C. Ramis, 2007: Analysis of the environments of seven Mediterranean tropicallike storms using an axisymmetric, nonhydrostatic, cloud resolving model. Nat. Hazards Earth Syst. Sci., 7, 41-56.

Frank, W. M., and P. E. Roundy, 2006: The role of tropical waves in tropical cyclogenesis. Mon. Wea. Rev., 134, 2397-2417.

Gray, W. M., 1975: Tropical cyclone genesis. Colorado State University Department of Atmospheric Sciences Paper 234, 121 pp.

Guishard, M. P., J. L. Evans, and R. E. Hart, 2009: Atlantic subtropical storms. Part II: Climatology. J. Climate, 22, 3574-3594.

Hart, R. E., 2003: A cyclone phase space derived from thermal wind and thermal asymmetry. Mon. Wea. Rev., 131, 585-615.
— and J. L. Evans, 2001: A climatology of the extratropical transition of Atlantic tropical cyclones. J. Climate, 14, 546-564.

,$- \ldots$, and C. Evans, 2006: Synoptic composites of the extratropical transition life cycle of North Atlantic tropical cyclones: Factors determining posttransition evolution. Mon Wea. Rev., 134, 553-578.

Hodges, K. I., 1994: A general method for tracking analysis and its application to meteorological data. Mon. Wea. Rev., 122, 2573 2586.

, 1995: Feature tracking on the unit sphere. Mon. Wea. Rev., 123, 3458-3465.

1999: Adaptive constraints for feature tracking. Mon. Wea. Rev., 127, 1362-1373.

— R. W. Lee, and L. Bengtsson, 2011: A comparison of extratropical cyclones in recent reanalyses ERA-Interim, NASA MERRA, NCEP CFSR, and JRA-25. J. Climate, 24, 48884906.

Hoskins, B. J., 1976: Baroclinic waves and frontogenesis. Part I: Introduction and Eady waves. Quart. J. Roy. Meteor. Soc., 102, $103-122$.

— 1996: On the existence and strength of the summer subtropical anticyclones. Bull. Amer. Meteor. Soc., 77, 1287-1292.

— , and P. J. Valdes, 1990: On the existence of storm-tracks. J. Atmos. Sci., 47, 1854-1864.

_ , and K. I. Hodges, 2002: New perspectives on the Northern Hemisphere winter storm tracks. J. Atmos. Sci., 59, 1041-1061.

Inatsu, M., H. Mukougawa, and S. Xie, 2002: Tropical and extratropical SST effects on the midlatitude storm track. J. Meteor Soc. Japan, 80, 1069-1076.

Jones, S. C., and Coauthors, 2003: The extratropical transition of tropical cyclones: Forecast challenges, current understanding, and future directions. Wea. Forecasting, 18, 1052-1092.

Jung, T., and Coauthors, 2012: High-resolution global climate simulations with the ECMWF model in project Athena: Experimental design, model climate, and seasonal forecast skill. J. Climate, 25, 3155-3172.

Kitabatake, N., 2008: Extratropical transition of tropical cyclones in the western North Pacific: Their frontal formation. Mon Wea. Rev., 136, 2066-2090.

- 2010: Impact of synthetic wind retrieval on tropical cyclone structures at the extratropical transition stage in the JRA-25 reanalysis. SOLA, 6, 77-80.

_ 2011: Climatology of extratropical transition of tropical cyclones in the western North Pacific. J. Meteor. Soc. Japan, 89, 309-325.

Knapp, K. R., M. C. Kruk, D. H. Levinson, H. J. Diamond, and C. J. Neumann, 2010: The International Best Track Archive for Climate Stewardship (IBTrACS) unifying tropical cyclone data. Bull. Amer. Meteor. Soc., 91, 363-376.

Kurihara, Y., M. A. Bender, and R. J. Ross, 1993: An initialization scheme of hurricane models by vortex specification. Mon. Wea. Rev., 121, 2030-2045.

Mctaggart-Cowan, R., J. T. J. Galarnequ, L. F. Bosart, R. W. Moore, and O. Martius, 2013: A global climatology of baroclinically influenced tropical cyclogenesis. Mon. Wea. Rev., 141, 1963-1989.

Miyasaka, T., and H. Nakamura, 2005: Structure and formation mechanism of the Northern Hemisphere summertime subtropical highs. J. Climate, 18, 5046-5065.

Murakami, H., and B. Wang, 2010: Future change of North Atlantic tropical cyclone tracks: Projection by a $20-\mathrm{km}-\mathrm{mesh}$ global atmospheric model. J. Climate, 23, 2699-2721.

Ogura, Y., H. Niino, R. Kumabe, and S. Nisimura, 2005: Evolution of a typhoon-like subtropical low causing severe weather over 
the Kanto area on 13 October 2003. J. Meteor. Soc. Japan, 83, 531-550.

Onogi, K. J., and Coauthors, 2007: The JRA-25 Reanalysis. J. Meteor. Soc. Japan, 85, 369-432.

Ooyama, K., 1969: Numerical simulation of the life cycle of tropical cyclones. J. Atmos. Sci., 26, 3-40.

Otkin, J. A., and J. E. Martin, 2004: A synoptic climatology of the subtropical Kona storm. Mon. Wea. Rev., 132, 1502-1517.

Rasmussen, E. A., and J. Turner, Eds., 2003: Polar Lows: Mesoscale Weather Systems in the Polar Regions. Cambridge University Press, 624 pp.

Reynolds, R. W., N. A. Rayner, T. M. Smith, D. C. Stokes, and W. Wang, 2002: An improved in situ and satellite SST analysis for climate. J. Climate, 15, 1609-1625.

Rotunno, R., and K. A. Emanuel, 1987: An air-sea interaction theory for tropical cyclones. Part II: Evolutionary study using a nonhydrostatic axisymmetric numerical model. J. Atmos. Sci., 44, 542-561.

Sauliere, J., D. J. Brayshaw, B. Hoskins, and M. Blackburn, 2012: Further investigation of the impact of idealized continents and SST distributions on the Northern Hemisphere storm tracks. J. Atmos. Sci., 69, 840-856.

Schenkel, B. A., and R. E. Hart, 2012: An examination of tropical cyclone position, intensity, and intensity life cycle within atmospheric reanalysis datasets. J. Climate, 25, 3453-3475.

Simmons, A., S. Uppala, D. Dee, and S. Kobayashi, 2007: ERAInterim: New ECMWF reanalysis products from 1989 onwards. ECMWF Newsletter, No. 110, ECMWF, Reading, United Kingdom, 25-35.

Smith, R. K., 1997: On the theory of CISK. Quart. J. Roy. Meteor. Soc., 123, 407-418.
Strachan, J., P. L. Vidale, K. Hodges, M. Roberts, and M.-E. Demory, 2013: Investigating global tropical cyclone activity with a hierarchy of AGCMs; the role of resolution. J. Climate, 26, 133-152.

Tochimoto, E., and T. Kawano, 2012: Development processes of "baiu" frontal depressions. SOLA, 8, 9-12.

Valdes, P. J., and B. J. Hoskins, 1989: Linear stationary wave simulations of the time-mean climatological flow. J. Atmos. Sci., 46, 2509-2527.

Wang, H., and M. Ting, 1999: Seasonal cycle of the climatological stationary waves in the NCEP-NCAR reanalysis. J. Atmos. Sci., 56, 3892-3919.

Yanase, W., and H. Niino, 2005: Effects of baroclinicity on the cloud pattern and structure of polar lows: A high-resolution numerical experiment. Geophys. Res. Lett., 32, L02806, doi:10.1029/ 2004GL020469.

—_ and _ 2007: Dependence of polar low development on baroclinicity and physical processes: An idealized highresolution numerical experiment. J. Atmos. Sci., 64, 30443067.

, and A. Abe-Ouchi, 2010: A numerical study on the atmospheric circulation over the midlatitude North Pacific during the last glacial maximum. J. Climate, 23, 135-151.

-, M. Satoh, H. Yamada, K. Yasunaga, and Q. Moteki, 2010: Continual influences of tropical waves on the genesis and rapid intensification of Typhoon Durian (2006). Geophys. Res. Lett., 37, L08809, doi:10.1029/2010GL042516.

,-- H. Taniguchi, and H. Fujinami, 2012: Seasonal and intraseasonal modulation of tropical cyclogenesis environment over the Bay of Bengal during the extended summer monsoon. J. Climate, 25, 2914-2930. 